\title{
Real options valuation under uncertainty
}

\author{
Marie Lambert ${ }^{a}$ \\ University of Liège
}

\author{
Manuel Moreno ${ }^{b}$ \\ University of Castilla La-Mancha
}

Federico Plataniac $^{c}$
University of Liège

August 24, 2015

\begin{abstract}
In this paper we develop a novel valuation model and methodology to value a pharmaceutical $R \& D$ project based on real options approach. The real options approach enables the possibility of optimally abandon the project before completion whenever the investment cost turns out to be larger than the expected net cash flow stream. On the other hand, the proposed model accounts for two different sources of uncertainty, those are technical and economic risk. This model incorporates a novel economic state vector where each economic state captures the interaction among different market and economic forces using Fourier series as the particular basis for the economic function space. In this sense, Fourier series are considered as an aggregate of forces playing a relevant role in the process evolution determining the cash flow structure and also allowing us to properly define an economic scenario where the project will be developed.
\end{abstract}

Keywords: Real options, R\&D, Economic risk, Fourier series, Pharmaceutical industry, Risk factor.

JEL classification: G12, G17, G32, C22, C63.

\footnotetext{
${ }^{a}$ Department of Finance, HEC Management School, University of Liège. Rue Louvrex 14, Bldg. N1, 4000 Liège, Belgium. E-mail: Marie.Lambert@ulg.ac.be

${ }^{\mathrm{b}}$ Department of Economic Analysis and Finance, University of Castilla La-Mancha, Cobertizo de San Pedro Mártir, s/n, 45071 Toledo, Spain. Phone: (34) 925268800. Fax: (34) 925268801. E-mail: manuel.moreno@uclm.es.

${ }^{\mathrm{c}}$ Corresponding author. Department of Finance, HEC Management School, University of Liège. Rue Louvrex 14, Bldg. N1, 4000 Liège, Belgium. E-mail: federico.platania@ulg.ac.be; platania.federico@gmail.com
} 


\section{Introduction}

The pharmaceutical industry is one of the most dynamic and research-intensive industries in the world. One distinctive characteristic of this sector is the high level of investment in research and development, in fact the pharmaceutical industry has one of the highest R\&D budget to sales revenue ratio across industries. The aim of this paper is to provide a comprehensive tool and methodology to value an $R \& D$ project considering that it is subjected to technical and economic uncertainty. Here we focus the attention on pharmaceutical $R \& D$ projects, however the model and methodology used can be easily extrapolated to any industry, say for instance mining projects.

Developing a new medicine is a challenging endeavour and the chances of success are extremely low, there are several complex forces, both economic and technical, governing the drug development process that are not entirely understood. The first obstacle arises during the early discovery stage when the company has to wisely assign the appropriate amount of both financial and scientific resources. Although the total cost to develop a new medicine varies from one to another it heavily depends on the kind of compound used, the drug under development, and the likelihood of failure. In terms of time to completion, a pharmaceutical $R \& D$ process can take, roughly speaking, between ten to fifteen years since the early-stage discovery of a new compound up to the marketing approval and market launch of the product, again it heavily depends on the drug or treatment. For some innovative drugs or treatments both cost and time to completion are a significant source of uncertainty and constitute the cost of innovation. On the other hand, many "new" medicines or treatments are just improvements on existing drugs, in this case the cost and time to completion are quite standardized and, although there is some uncertainty, the $\mathrm{R} \& \mathrm{D}$ financial and technological cost is considerable lower.

The pharmaceutical market is extremely complex and has divided the public opinion in several controversial topics such as animal testing, drug prices, lack of research interest for certain diseases, public funding, and so on. As any other private company, pharmaceutical companies are ultimately focused on increasing shareholder value. The public perception that privately research funding is solely motivated by profit has increased the friction between shareholders' return expectations and the public notion of fairness. On this regard, it is important to point out that no matter how big a pharmaceutical company is, it can only cover a small portion of breakthrough R\&D projects. Therefore, most pharmaceutical companies have to choose with financial wisdom each project because simply they cannot afford to invest when the affected population is too poor to buy the drug or the market niche is just too small to achieve a reasonable return on the investment. Recently, the 2014 Ebola outbreak has revealed the lack of resources and effort assigned to fight this virus while it was limited or contained within the African border, and the increased interest when the virus crossed the European and American border and "opened a new market". In this 
paper we are not going to discuss such controversial ethical issues, however our proposed model incorporates a novel economic state vector where each economic state captures the interaction among different market and economic forces using Fourier series as the particular basis for the economic function space. Hence, our model can be used to depict any extreme economic situation and properly value an $R \& D$ project targeting such market. Furthermore, since most drugs introduced by the pharmaceutical industry are developed with some contribution from the public sector, see for instance Cockburn and Henderson (2000), our model can be used to determine the appropriate amount of taxpayer's money to allocate in a specific project. On this regard, it is worth to mention that public opinion is a strong force which can heavily affect the project value, its effects can also be modelled with the appropriate terms in the Fourier expansion.

The objective of this paper is to provide a powerful and flexible valuation model and technology accounting for technical and economic risk and considering all those relevant forces playing a significant role in the project valuation and decision making process. The remainder of this paper is structured as follows: Section 2 is devoted to literature review. In Section 3 we identify those economic risk factors affecting the Pharmaceutical return process, and we also disentangle the interaction across factors via spectral analysis. Section 4 presents the valuation model, technicalities, and implications. In Section 5 we illustrate the numerical implementation of the posited model and methodology, we perform a sensitivity and stress test analysis to determine the response of the model to different scenarios. Finally, in Section 6 we make some concluding comments.

\section{Literature review}

There is a vast amount of literature based on real options and its application to R\&D. Most of the academic literature based on real option valuation consider as exogenous variable the value of the project conditional to the successful completion of the research and development phase. For instance, Madj and Pinduck (1987) use a Geometric Brownian motion process to model the time evolution of the project's market value. The authors show that the arrival of new information might lead the firm to depart from the spending scenario originally planned, and conclude that traditional discounted cash flow criteria do not capture the managerial decision flexibility and for that reason are inadequate to properly value projects where the spending decisions and cash outlays occur sequentially over time, there is a maximum rate at which outlays and construction can proceed, and the project yields no cash return until it is actually completed. Furthermore, assuming that the gross project value follows a Geometric Brownian motion, Trigeorgis (1993) analyses the valuation of flexible capital budgeting projects with a collections of real options and examines the interactions among these options identifying situations where option interactions can be small or large, negative 
or positive. Pennings and Sereno (2011) value a compound R\&D option assuming a geometric Brownian motion process for the underlying value of the project and considering a Poisson random variable to depict the technical failure probability.

On this regard, our approach is closer to the work of Berk et al. (2003) and Schwartz (2004) where the cash flows from the R\&D project are modelled. In more detail, Berk et al. (2003) develops and analyses a single $R \& D$ investment project modelling the cash flows from the project with two stochastic processes, one of them tracking any possible catastrophic event and the other process modelling the conditional cash flows the project would have produced if it were completed. The authors assume that the cash flows last forever allowing them to value the completed project using a continuously compounded version of the growing perpetuity formula. On the other hand, Schwartz (2004) implements a simulation approach to value patents and patent-protected R\&D projects assuming two stochastic differential processes, one of them for the cost-of-completion and the other for the cash flows generated from the project, and introduces the probability of any catastrophic event with a Poisson probability. In this paper we consider the net cash flow as the underlying variable, however since this variable takes into consideration the production and marketing cost it could yield a negative cash flow stream. Therefore, we assume that the net cash flow of a successful project is given by an Arithmetic Brownian motion process plus a time dependent component depicts by the Fourier series. On this regard, Copeland and Antikarov (2001, Chapter 5) claim that cash flow streams, and thus present values, can be negative. Accordingly, Alexander et al. (2012) assume that the project's value does not necessarily remain positive during the whole project's life and model the intrinsic value of the project with an Arithmetic Brownian motion process which allows the underlying to become negative. Under this assumption, the authors find analytical formulas for European calls and puts on dividend-paying assets and provide a numerical algorithm for Americanstyle options based on an Arithmetic Brownian motion process. It is worth point out that in this paper we model the stochastic process with an Arithmetic Brownian motion because we intentionally decided to model the net cash flow as the underlying variable, however the methodology applied here can be easily extrapolate to any other underlying variable following a Geometric Brownian motion or a mean reverting process.

An important feature of $R \& D$ projects is the uncertainty related with the cost to completion, for an in-depth look of this topic see, for instance, Hansen (1979), DiMasi et al. (1991), and particularly DiMasi et al. (2003) where the authors perform a thoroughly study of the research and development cost of 68 randomly selected new drugs of 10 different pharmaceutical companies and provide an estimate of the costs of pharmaceutical innovation. Also, Pindyck (1993) studies investment decisions when the project is subjected to two different sources of uncertainty, technical uncertainty and cost uncertainty. In this case, the author concludes that, although the sources and 
amounts of cost uncertainty greatly varies across projects, cost uncertainty has a deeper impact than technical uncertainty in terms of its effect on the investment rule and the value of the investment opportunity.

Further relevant literature about real option valuation includes, Childs and Triantis (1999) who examine dynamic $R \& D$ investment policies and the valuation of $R \& D$ programs in a contingent claims framework. The authors study the interaction between multiple R\&D projects cash flows and analyse how the firm may alter its funding policy over time. Smith and Nau (1995) compare the risk-adjusted discount-rate analysis, option pricing analysis, and decision analysis approaches for valuing risky projects. Posner and Zuckerman (1990) determine the optimal stopping time of an $R \& D$ project and characterize the expenditure strategy assuming a random $R \& D$ decision model without rivalry. McDonald and Siegel (1986) compare the optimal timing of investment for certain alternative combinations when the future net cash flow follows a Geometric Brownian motion process with and without jumps, and the cost of installation is fixed or stochastically modelled with also a GBM process. Gamba and Trigeorgis (2007) implement a multi-dimensional binomial algorithm for valuing options whose payoff depends on $\mathrm{N}$-dimensional state variables following correlated Geometric Brownian processes.

\section{Pharmaceutical industry and economic risk factors}

Economic forces not only affect the number of investment opportunities available in the Pharmaceutical industry but also play a key role in the cash-flow determination of a successful R\&D project. Consequently, economic uncertainty represents an essential risk factor affecting Pharmaceutical stock returns. This section is devoted to identify those economic risk factors driving the stock return process and the risk premium associated with each individual factor.

There is a vast number of economic risk factors with a potential impact in a Pharmaceutical company. For the sake of simplicity, in this paper we analyse two major forces. Firstly, as discussed in Fama and French (1989) the term yield spread (TYS) tracks the business cycle, therefore it constitutes a relevant force to be considered in the analysis. The TYS is computed as the yield difference between 10-year and 3-month Treasury constant maturity provided by the Federal Reserve database. As for the second force proxy we employ the VIX index, provided by the Chicago Board Options Exchange CBOE, which is considered as the barometer of investor sentiment and market volatility. As will be the case, each of these time series might arise as the interaction of factors with different characteristics, in particular, the interaction of factors with different periods. In order to disentangle this interaction, we perform an spectral analysis of each time series and we search for those factors with higher spectral density. 
Figures 1 and 2 present the demeaned TYS and VIX series, respectively, and the corresponding spectra. ${ }^{a}$ As for the TYS series, the spectrum reveals four dominant frequencies driving the process, those frequencies are $0.0302,0.1209,0.1813$, and 0.4231 , indicating a period of $33,8,5.5$, and 2.4 years, respectively. The business cycle is normally associated to a period of 8 years, not surprisingly the highest power spectral density corresponds to this frequency. Moreover, there is a second spectral peak at the frequency corresponding to the 5.5 years period. This period may be associated to the Kitchin cycle which accounts for time lags in information movements, for further information about the Kitchin cycle we refer to the original paper Kitchin (1923). As for the other two frequencies, the power spectral density still stands out from the noise but the relevance decreases, in any case the underlying frequencies reveal a long run and a short period of 33 and 2.4 years, respectively.

On the other hand, the spectrum associated with the VIX series presents a not well defined peak at a rather short frequency. In fact, the full width at half maximum (FWHM) goes from 0.06 to 0.185 frequency, that is a period ranging from 5.4 to 16.5 years.

\section{[FIGURES 1 and 2 AROUND HERE]}

In order to replicate the TYS and VIX series we consider a Fourier series with four and one term in the expansion, respectively, that is

$$
\begin{aligned}
F S_{T Y S}(t)= & A_{1} \cdot \cos \left(2 \pi f_{1} \cdot t+\phi_{1}\right)+A_{2} \cdot \cos \left(2 \pi f_{2} \cdot t+\phi_{2}\right)+A_{3} \cdot \cos \left(2 \pi f_{3} \cdot t+\phi_{3}\right) \\
& +A_{4} \cdot \cos \left(2 \pi f_{4} \cdot t+\phi_{4}\right) \\
f_{1}= & 0.0302 ; f_{2}=0.1209 ; f_{3}=0.1813 ; f_{4}=0.4231 \\
F S_{V I X}(t)= & B_{1} \cdot \cos \left(2 \pi g_{1} \cdot t+\varphi_{1}\right)
\end{aligned}
$$

and we search the estimates for the parameters by solving the following non-linear optimization problem

$$
\begin{aligned}
& \min \left(S R \hat{\theta}_{T Y S}\right)=\sum_{t}\left(\text { Term Yield Spread } t-F S_{T Y S}(t)\right)^{2} \\
& \min \left(S R \hat{\theta}_{V I X}\right)=\sum_{t}\left(\operatorname{VIX}_{t}-F S_{V I X}(t)\right)^{2}
\end{aligned}
$$

Since the VIX's spectra does not provide a well define peak, we estimate the frequency imposing a boundary condition to the FWHM space, that is $g_{1} \in[0.06,0.185]$. Tables 1 and 2 provide the parameters estimates.

${ }^{\mathrm{a}}$ We analyse the demeaned series in order to avoid a spectral peak at the zero frequency 
[TABLES 1 and 2 AROUND HERE]

Figures 3 and 4 show the time evolution of the demeaned TYS against the Fourier series with two and four terms in the expansion, respectively. Figure 5, on the other hand, presents the time evolution of the demeaned VIX against the Fourier series with only one term in the expansion.

[FIGURES 3 to 5 AROUND HERE]

Hence, we identify each term in the Fourier expansion as a possible factor in the determination of the excess of return. In order to test the relevance and the premium associated with an individual factor we will use the Fama-MacBeth test proposed by Fama and MacBeth (1973). The two stage Fama-Macbeth regression estimates the premium rewarded to a particular risk factor exposure, that is, how much return you would expect to receive for a particular beta exposure to that factor. The first stage regressions are a set of time series regression of each asset or portfolio's return on the factors, that is

$$
r_{i, t}^{e}=\alpha_{i}+\sum_{j} \beta_{i, j} \cdot F_{j t}+\epsilon_{i t}
$$

where $r_{i}^{e}$ represents a $t \times 1$ vector of excess of returns, $F_{j t}$ is a $t \times j$ matrix of factors, $\beta_{j, i}$ represents a $j \times 1$ vector of factor loadings, $\alpha_{i}$ is the intercept, $j$ and $i$ represent the number of factors and the number of assets or portfolios, respectively. This regression reveals to what extent each asset's or portfolio's return is affected by each factor.

The second stage regressions calculate the premium rewarded to each factor exposure following a set of cross-sectional regressions

$$
r_{i t}^{e}=\lambda_{0 t}+\sum_{j} \lambda_{j t} \cdot \beta_{i j}+\eta_{i t}
$$

where the independent variables, $\beta_{i j}$, are always the same for every regression, each $\lambda_{t j}$ is a $t \times 1$ vector of factor premium, and $\lambda_{0 t}$ is the intercept. Note that for each factor we have a time series of factor premium where the t-statistic is calculated as follows

$$
\frac{\overline{\lambda_{j}}}{\overline{\sigma_{j}} / \sqrt{T}}
$$

where $\overline{\lambda_{j}}$ and $\overline{\sigma_{j}}$ represent the mean and standard deviation of each factor premium and $\mathrm{T}$ is the length of the time series.

First, we analyse the premium associated to each individual factor by itself. Table 3 presents the estimated premium and significance of each factor individually. Results reveal that, in this analysis, the risk factor of 33 years period is the only factor where the null hypothesis cannot be 
rejected $\left(H_{0}: \lambda=0\right)$. Furthermore, in Table 4 we analyse the four factors associated with the TYS and the factor associated with the VIX series all together, and also different combinations of factors. We can see that, systematically, the null hypothesis cannot be rejected for the 33 years period factor, which indeed cannot be consider as a relevant factor. In contrast, factors with period 5.5 and 2.4 years consistently deliver significant premiums for most factor combinations. On the other hand, an interesting analysis arises regarding those factors with 8 and 10 years period. We can see that both factors provide significant premiums when they are analysed individually, however when we incorporate further factors in the analysis the significance level decreases. Indeed, this may be indicating some sort of cointegration between factors. To sum up, in terms of asset valuation, we can see that the three factors basket composed of $\lambda_{2}, \lambda_{3}$, and $\lambda_{4}$, that is the factors with the underlying period of $2.4,5.5$, and 8 years, provides a combination where all three premiums rewarded are statistically significant at least at $10 \%$.

[TABLES 3 and 4 AROUND HERE]

\section{$4 \quad$ R\&D valuation model}

Consider, for instance, a pharmaceutical $R \& D$ project for the development of a new drug. The very nature of such project and the potential impact on human health make the pharmaceutical industry quite unique and risky. There are several strict and well regulated stages since the early-stage drug discovery up to the marketing approval and market launch of the product. Figure 6 presents an illustrative schedule of a generic pharmaceutical R\&D project.

\section{[FIGURE 6 AROUND HERE]}

The overall project's life can be divided into two mayor phases, firstly the research and development phase and secondly the market phase. During the early-stage of the research and development phase, a new compound which may potentially derive into a marketable drug is either discovered or designed. Once the compound is successfully identified as a potential drug and synthesized the project moves to the next stage. During the preclinical and clinical development the drug must successfully complete a number of well regulated stages. Firstly, the preclinical stage covers the laboratory and animal testing, and it is normally during this stage when the company applies for a patent. If and only if the drug successfully completes the preclinical stage, it accesses the clinical stage which can be divided into clinical phase I, II, and III. During the clinical phase I, the drug or treatment is tested in a small group of healthy volunteers in order to determine the safe dosage, evaluate its safety, and to identify possible side effects and toxicity. During the clinical phase II, the drug or treatment is tested on a relative large group of subjects (100-300) with the condition that 
the drug is intended to treat in order to further evaluate its safety and efficacy. Finally, the clinical testing phase III consists of large scale trials, usually a few thousands, to confirm the safety and efficacy of the drug or treatment and to further monitor possible side effects. The final stage in the research and development phase is the marketing approval, once again if and only if the drug has successfully completed each and every preceding stage, the regulatory authority decides whether the drug is approved for patient use or not. If the marketing approval is granted the project moves to the market phase where the appropriate marketing strategy should be established and the product is market launched.

During the patent's life, the company is entitled to a set of exclusive rights protecting the project from market competitors for a limited period of time. However, market competition is not the only force that jeopardises the successful completion of the project. It is well established in the literature, see for instance Brealey and Myers (2000), that an R\&D project faces two different sources of risk, those are the economic and technical risk. Technical or technological risk takes into account the inherent uncertainty about the successful completion of each stage during the drug development phase, for instance, an extreme side effect during the clinical testing would lead to a failure event. On the other hand, economic risk deals with both market uncertainty such as sales volume, pricing levels, market competitors, and other economic factors such as interest rates, inflation, growth rate. Indeed, in order to effectively value these sort of projects we have to be able to properly capture both sources of risk at the appropriate time.

\subsection{Technical uncertainty}

Technical or technological risk is the primary source of uncertainty during the drug development process, in fact, most drugs undergoing the preclinical and clinical stage do not obtain the regulatory authority's approval. Since each stage must be preceded by the successful completion of the previous one, the failure of one stage produces the overall project termination. On the other hand, we assume that once the drug successfully passes the preclinical and clinical test and finally achieves the regulatory authority's approval technical risk virtually vanishes. On this regard, it is widely spread the use of a Poisson process to model technical or technological risk (see for instance Pennings and Sereno (2011), Schwartz (2004), among others). The Poisson probability mass function (pmf) is given by

$$
f(k ; \lambda)=\frac{\lambda^{k} e^{-\lambda}}{k !}
$$

where $\lambda>0$ is the Poisson parameter, and $k=0,1,2, \ldots, \infty$ defines the number of events. Generalizing $k=1,2, \ldots, \infty$ as any possible technical event and $k=0$ as no technical event, we have that 


$$
\begin{aligned}
\text { Probability of success } & =e^{-\lambda} \\
\text { Probability of technical failure } & =\sum_{k=1}^{\infty} \frac{\lambda^{k} e^{-\lambda}}{k !}=1-e^{-\lambda}
\end{aligned}
$$

Hence, the expected project value conditional to technical risk is given as

$$
E\left[V_{t} \mid \text { Technical Risk }\right]=V_{t}(k=0) \cdot e^{-\lambda}+V_{t}(k=1,2, \ldots, \infty) \cdot\left(1-e^{-\lambda}\right)
$$

where

- $V_{t}(k=0)$ is the value of a successful project

- $V_{t}(k=1,2, \ldots, \infty)$ is the residual value of a failing project

Note that a failed project might increase the stock of knowledge of the company. However, it is common use to assume that the outcome of a failure is a worthless project. Under this assumption, technical risk can be consider as a premium over the risk free rate and during the development process the discount factor is given by $e^{-r_{d} t}=e^{-(r+\lambda) t}$, where $\lambda$ represents the annual rate of failure and $r$ the risk-free rate. Note that, as stated above, technical risk vanishes after the regulatory authority's approval, hence this premium is only valid during the drug development phase.

\subsection{Economic and market uncertainty}

So far things are fairly easy but we have only dealt with technical risk. Economic risk takes into account those factors affecting market conditions, not determining the successful completion in technological terms but defining the cash flow structure of a successful project which gives rise to the project's abandon option. In this fashion, economic risk not only comprehends macro and microeconomic figures but also certain project specific forces and circumstances driving the cash in and out flow, for instance an outbreak of influenza would drive an increase in market sales for those specific medicines or the 2014 Ebola outbreak that pushed the use of the experimental drug "ZMapp" in humans. Note that we have intentionally used the sentence "successful project", that is because we have divided the project into two mayor phases, the research and development and the market phase. As stated above, during the research and development phase technical risk is the dominant source of uncertainty and it vanishes as the drug successfully overcomes every single stage in the development process and finally achieves the corresponding approval, those projects reaching the market phase are the "successful projects". Once the drug reaches the market phase, there are several forces playing a significant role and we have called this source of uncertainty economic risk, however it is important to remember that only a "successful project" will face economic risk. 
We can easily realise that measuring economic risk is not a trivial endeavour, in fact, creating a framework where every force affecting the project is considered is literally impossible. On this regard, it is common use to model the evolution of the project or the evolution of the cash flow as a stochastic differential equation

$$
d C_{t}=\mu(C, t) d t+\sigma(C, t) d W
$$

where the process can take the form of a Geometric Brownian motion, Arithmetic Brownian motion, or an Ornstein-Uhlenbeck process. We can also find a more realistic and sophisticated framework, as the one proposed by Schwartz (2004), where the author models both the cash flow and the cost of completion with a stochastic differential equation.

As long as we stick with one stochastic factor, all these models share that the only source of uncertainty comes from a random walk weighted by $\sigma(C, t)$, that is the diffusion term. ${ }^{\mathrm{b}}$ It seems fairly obvious that a simple diffusion model cannot account for a realistic variety of forces playing a key role during the project's market phase. In particular, neither of these models can properly account for any seasonal component which, for instance, plays a primary role in the outbreaks of the $\mathrm{flu}$, plus neither consider the effect of the business cycle nor any other relevant force. At this point it is worth to wonder whether such models are an oversimplification and which forces do really make an impact in terms of project valuation. Of course there is not one right answer, each project must be analysed in excruciating detail to determine the appropriate set of relevant forces, but it seems fair to conclude that a simple diffusion model is just a naive simplification of the market structure.

In what follows we consider that the net cash flow stream, $C_{t}$, of a successful project is given by a latent variable, $Y_{t}$, depicted by an Arithmetic Brownian motion process plus a time dependent component described by the Fourier series, that is

$$
\begin{aligned}
C_{t} & =f(t)+Y_{t} \\
d Y_{t} & =\mu d t+\sigma d W_{t} \\
f(t) & =\text { Fourier Series }
\end{aligned}
$$

where $\{(\mu, \sigma) \in \mathbb{R}\}$. Note that, applying Ito's lemma to equation [13] the net cash flow dynamic is depicted by

$$
d C_{t}=\left(\mu+\frac{d f}{d t}(t)\right) d t+\sigma d W_{t}
$$

\footnotetext{
${ }^{\mathrm{b}}$ The option pricing literature is very fructiferous in terms of models with two, or even three stochastic factors, see for instance Chen 1996
} 
The net cash flow stream takes into consideration the production and marketing cost, in consequence it could yield a negative rate, thus an Arithmetic Brownian motion process is a suitable representation of the underlying process. Under this framework, the solution of the underlying process and the net cash flow at any given time $t$, under the risk neutral probability $\mathbb{P}^{Q}$, is represented by

$$
\begin{aligned}
Y_{t} & =Y_{0} e^{r t}+\sigma \int_{0}^{t} e^{r(t-s)} d W_{s}^{Q} \\
C_{t} & =\left(C_{0}-f(0)\right) e^{r t}+f(t)+\sigma \int_{0}^{t} e^{r(t-s)} d W_{s}^{Q}
\end{aligned}
$$

where $W_{t}^{Q}$ is a standard Wiener process under the risk-neutral measure $\mathbb{P}^{Q}$.

In the same fashion as in Schwartz (2004), the cash flow stream starts when the R\&D project is market launched, before this stage the process describes the net cash flow that the project would have produced if it were successfully completed. Once the medicine or treatment is market launched the value of the project depends exclusively on the net cash flow generated. Hence, using the Merton (1973) no-arbitrage technique the project value, $V\left(C_{t}, t\right)$, must satisfy the following partial differential equation

$$
\frac{\partial V}{\partial t}+r C \frac{\partial V}{\partial C}+\frac{\sigma^{2}}{2} \frac{\partial^{2} V}{\partial C^{2}}-r V=0
$$

subject to the appropriate terminal condition $V(C, T)$, where $T$ represents the patent expiration.

The novel component in this model is the ad hoc incorporation of the Fourier series, $f(t)$, accounting for any economic, market, and specific force affecting the project and not captured by the underlying stochastic differential equation. In this sense Fourier series should be considered as an aggregate of forces playing a relevant role in the process evolution and determining the cash flow structure. Note that Fourier series provides a great deal of flexibility as, by Carleson's theorem, it converges almost everywhere for a $L^{2}$ function. Therefore, $f(t)$ allows us to properly define a scenario where the project will be developed, such scenario is tailor made based on the characteristics of each project, the influence and exposure to certain forces, and so on. On this regard, we might not have a precise ex-ante projection of such scenario, for instance, we might know that the business cycle represents a risk factor but we might not know how deeply it affects the cash flow stream. Hence, let us represent the economic uncertainty by the state vector

$$
\Phi^{(j)} \text { with } j \in \mathbb{N}
$$

where each state defines a case scenario depicted by a concrete selection of terms in the Fourier expansion and represents the aggregate of forces. It is important to stress out that a state scenario 
does not attempt to replicate a precise future outcome but rather establishes an alternative future development. Each state determines the cash flow structure of a successful project and consequently the managerial decision of ceasing or continuing the project. Thus, the expected patent value conditional to a certain economic state is given as

$$
V\left(t, C_{t}, I_{t} ; \Phi^{(j)}\right)=E\left[V \mid \Phi^{(j)}\right] \text { with } j \in \mathbb{N}
$$

where $C_{t}$ and $I_{t}$ represent the net cash flow structure once the drug obtains the marketing approval and the investment structure during the research and development phase, respectively.

Note that the conditional patent value is constrained to the future development of certain state, which of course is uncertain. Therefore, since $\Phi$ is defined as a discrete state vector, an essential piece of the puzzle is the appropriate definition of its mass probability function. On this regard, Huchzermeier and Loch (2001) define a one-dimensional parameter $i$ to model the product performance. The authors claim that this performance may unexpectedly improve with probability $p$, or it may deteriorate with probability $(1-p)$ and they generalize the binomial distribution by allowing the performance "improvement" and "deterioration" over $N$ performance states. We can easily accommodate a similar probability mass function defining two states in the economic state vector, that is, $j=1,2$. However, as stated above, each state represents the aggregate of forces acting over the project, and therefore is very project specific, so we will implement a rather Bayesian approach and assign a prior probability to each scenario. Note that each state can be defined in several ways, we can tailor made it based on our own expectations, we can define it based on analyst expectations, and so on. Hence, let us define the state vector probability mass function in general terms as

$$
g\left(\Phi^{(j)}\right)=\operatorname{Pr}\left(\Phi=\Phi^{(j)}\right)=p_{j}
$$

where $p_{j}$ represents the probability that the state $\Phi^{(j)}$ turns out real. Hence, under this framework the patent value is determined by

$$
\text { Patent Value }=\sum_{j} V\left(t, C_{t}, I_{t} ; \Phi^{(j)}\right) \cdot g\left(\Phi^{(j)}\right)
$$

\subsection{Risk premia and risk factors}

We have already stated that during the research and development phase the dominant source of uncertainty comes from technical or technological risk. Following a similar approach as Pennings and Sereno (2011) and Schwartz (2004), we have used a Poisson process to account this source of risk. We have also pointed out that technical risk can be considered as a premium over the risk-free rate, for that reason during this stage the discount factor yields $e^{-r_{d} t}=e^{-(r+\lambda) t}$. However, we have 
assumed that during the market phase the drug has already achieved the marketing approval and there is no technical uncertainty. Then, technical uncertainty vanishes, economic and market risk are the dominant sources of uncertainty and the instantaneous expected rate of return of the project is given as

$$
E\left[r_{p}\right]=\sum_{j} E\left[\frac{d C_{t}}{C_{t}} \mid \Phi^{(j)}\right] \cdot g\left(\Phi^{(j)}\right)
$$

Under our model representation the cash flow streams start once the drug is launched and the net cash flow process of a successful project is given by a latent Arithmetic Brownian motion process plus a time dependent component depicts by the Fourier series, just as given by equations [13] to $[15]$.

Let us assume that the excess of return of a pharmaceutical company, that is the premium over the risk free rate, is a function of the return on every active project. Hence, we can define it as a function of those economic forces driving each project cash flow process, that is

$$
r_{t}^{e}=F\left(f^{(j, i)}(t) ; \Phi^{(j)}\right)
$$

where $f(t)$ is given by equation [15], $i$ represents each active project, and $j$ represents each state in the economic state vector. Note that equation [25] cannot be considered just an aggregate of equation [24] for several reasons, for instance, there may be a non-linear interaction or synergy across projects, there may be a project financed with a government grant, or simply those economic and market forces may affect with different intensity different projects, in this sense it seems reasonable to assume that the business cycle has a deeper impact over aesthetic medicines than cancer treatments. Further information about project interactions can be found in Loch and Kavadias (2002) where the authors develop a dynamic model of resource allocation taking into account multiple project iterations.

\section{$5 \quad$ Numerical results}

This section is devoted to illustrate the numerical implementation of the posited model and methodology. Let's assume that the research team has already identified a compound which may potentially be used to engineer a new diabetes medication. At this stage the Board has to face the first abandon option, that is, they have to decide whether this project constitutes a valid investment opportunity and apply for a patent protection or drop it before going any farther into the development phase. For the sake of simplicity, let us assume that there is no uncertainty about the time and cost to completion if the project successfully overcomes every stage in the development process. Note that most of the investment cost is spent to develop the drug and it can also be modelled stochastically, 
see for instance Schwartz (2004). However, we prefer to keep the numerical example as simple as possible and focus the attention on economic and market uncertainty rather than development issues, although a stochastic process for the cost and time to completion could be easily implemented. According to the "Tufts Center for the Study of Drug Development" (see DiMasi et al. 2014), the total out-of-pocket cost per approved new compound is about 1.400 Millions (in 2013 \$). Based on this information, Table 5 summarises the representative out-of-pocket investment cost and schedule by year.

\section{[TABLE 5 AROUND HERE]}

\subsection{Technical uncertainty}

In the previous section we have established that during the development phase the project can either fail or be abandoned. Technical risk accounts for the probability of a failure event due to a technical or technological reason within the development phase, and we have generalized the Poisson distribution allowing for the probability of success and technical failure. According to the "2015 biopharmaceutical research industry profile" report, provided by PhRMA, the average time to develop a drug is about 10 years and the percentage of drugs entering clinical trials resulting in an approved medicine is less than $12 \%$. Hence, assuming that only $12 \%$ of such projects successfully overcome every stage in the development phase and a development period of 10 years, the annual rate of failure is given as

$$
\begin{aligned}
e^{-10 \cdot \lambda} & =0.12 \\
\lambda & =0.2120
\end{aligned}
$$

We have also assumed that the outcome of a failure is a worthless project, hence, during the development process the discount factor is given by $e^{-r_{d} t}=e^{-(r+0.2120) t}$, where $r$ represents the risk-free rate.

\subsection{Economic and market uncertainty}

We have determined that the net cash flow stream from sales revenues, marketing and production cost starts when the medication gets the marketing approval and it is launched, which is expected to occur on period 10. Let us assume that the patent will be granted in 4 years for a limited period of 20 years. When the patent expires market competition forces sales to virtually zero, meaning that based on the schedule the company can only benefit from this project for 14 years starting at market launch. This assumption generates the boundary condition, $V(T)=0$, on equation [19], where $T$ 
represents the patent expiration. Furthermore, in section 3 we have performed a Fama-MacBeth test and we have identified the economic risk factors driving the valuation process, those are the factors with period of $2.4,5.5$, and 8 years, and we have estimated the parameters in the Fourier expansion as given in Table 1. Note that the parameters defining the behaviour of the economic force, and hence of each factor, are the frequency $(f)$ and the phase $(\phi)$ parameter. On the other hand, the amplitude parameter defines the intensity of such force or cycle over the net cash flow stream, indeed a project dependent parameter.

Let us define three states in the economic state vector, each of them will represent an economic benchmark determined by the top-3 best selling diabetes medicines commercialized by American Pharmaceuticals, these are

- $\Phi^{1}: g\left(\Phi^{1}\right)=1 / 3 \Rightarrow$ Scenario 1: Januvia (Merck \& Co., Inc.)

- $\Phi^{2}: g\left(\Phi^{3}\right)=1 / 3 \Rightarrow$ Scenario 2: Janumet (Merck \& Co., Inc.)

- $\Phi^{3}: g\left(\Phi^{2}\right)=1 / 3 \Rightarrow$ Scenario 3: Humalog (Eli Lilly and Company)

Figure 7 presents the quarterly sales revenue from 3Q-2009 to 1Q-2015 of each medicine. For each state, we consider that the initial cash flow parameter, $C_{0}$, in equation [18] is given by the sales revenue at time 3Q-2009, and we proxy the volatility, $\sigma$, by the standard deviation of the process, hence

$$
\begin{array}{ll}
\Phi^{1} \Rightarrow & C_{0}=490 \text { Million } \$ \text { and } \sigma=200 \text { Million\$ } \\
\Phi^{2} \Rightarrow & C_{0}=173 \text { Million } \$ \text { and } \sigma=115 \text { Million\$ } \\
\Phi^{1} \Rightarrow & C_{0}=500 \text { Million\$ and } \sigma=75 \text { Million\$ }
\end{array}
$$

\section{[FIGURE 7 AROUND HERE]}

Moreover, considering the three economic risk factors defined in Section 3, we defined the Fourier component in equation [15] under each state scenario as follows

$$
\begin{aligned}
& f\left(t \mid \Phi^{1}\right)=\hat{A}_{0}^{1}+\hat{A}_{2}^{1} \cdot \cos \left(2 \pi f_{2} \cdot t+\phi_{2}\right)+\hat{A}_{3}^{1} \cdot \cos \left(2 \pi f_{3} \cdot t+\phi_{3}\right)+\hat{A}_{4}^{1} \cdot \cos \left(2 \pi f_{4} \cdot t+\phi_{4}\right) \\
& f\left(t \mid \Phi^{2}\right)=\hat{A}_{0}^{2}+\hat{A}_{2}^{2} \cdot \cos \left(2 \pi f_{2} \cdot t+\phi_{2}\right)+\hat{A}_{3}^{2} \cdot \cos \left(2 \pi f_{3} \cdot t+\phi_{3}\right)+\hat{A}_{4}^{2} \cdot \cos \left(2 \pi f_{4} \cdot t+\phi_{4}\right) \\
& f\left(t \mid \Phi^{3}\right)=\hat{A}_{0}^{3}+\hat{A}_{2}^{3} \cdot \cos \left(2 \pi f_{2} \cdot t+\phi_{2}\right)+\hat{A}_{3}^{3} \cdot \cos \left(2 \pi f_{3} \cdot t+\phi_{3}\right)+\hat{A}_{4}^{3} \cdot \cos \left(2 \pi f_{4} \cdot t+\phi_{4}\right)
\end{aligned}
$$

and we search the values of the intensity parameters by solving the following non-linear optimization problem 


$$
\begin{aligned}
\min \left(S R \hat{\theta^{1}}\right) & =\sum_{t}\left(\text { Januvia-Cash-Flow } t-C\left(t \mid \Phi^{1}\right)\right)^{2} \\
\min \left(S R \hat{\theta^{2}}\right) & =\sum_{t}\left(\text { Janumet-Cash-Flow }_{t}-C\left(t \mid \Phi^{2}\right)\right)^{2} \\
\min \left(S R \hat{\theta^{3}}\right) & =\sum_{t}\left(\text { Humalog-Cash-Flow }_{t}-C\left(t \mid \Phi^{3}\right)\right)^{2}
\end{aligned}
$$

where the structural parameters are given as $\hat{\theta^{1}}=\left(\hat{A}_{0}^{1}, \hat{A}_{2}^{1}, \hat{A}_{3}^{1}, \hat{A}_{4}^{1}\right), \hat{\theta^{2}}=\left(\hat{A}_{0}^{2}, \hat{A}_{2}^{2}, \hat{A}_{3}^{2}, \hat{A}_{4}^{2}\right)$, and $\hat{\theta^{3}}=\left(\hat{A_{0}^{3}}, \hat{A_{2}^{3}}, \hat{A_{3}^{3}}, \hat{A_{4}^{3}}\right)$, and the frequency and phase parameters as given in Section 3-Table 1. Table 6 provides the estimates of the intensity parameters under each state scenario.

The three state scenarios share the same risk-free rate. The usual benchmark for the risk-free rate is the treasury constant maturity provided by the Federal Reserve, however since the beginning of the financial crisis the US treasury yield is close to zero. Hence, we will use a risk-free rate of $1.5 \%$ although the current value is much lower.

\subsection{Project value and risk management}

Having defined the state vector and calibrated all the input parameters, we are ready to compute the value of this project. As shown in Figure 7, the market data of each benchmark medicine is provided in quarters. Hence, by assumption, we consider that the underlying process, $C_{t}$, defines the quarterized net cash flow stream. Then, we simulate each path considering a time increment of $\Delta t=1 / 4$, that is quarterly increment. The discrete cash flow at any time $t$ is given by equation [18]. Once the marketing approval is granted, the marketing and production cost are accounted into the net cash flow process. Therefore, discounting all the discrete cash flows up to market launch and summing them up could yield an aggregated negative value, for that reason it is considered an abandon option at market launch although there is no further investment in developing the drug. Note that the probability of an aggregated negative cash flow at market launch is the consequence of considering an Arithmetic Brownian Motion process plus the impact of the Fourier component over such process, therefore such probability tends to decrease as the economic state improves. Accordingly, at market launch the abandon option is given by

$$
V\left(t_{M L}, C_{t}, I_{t} ; \Phi^{(j)}\right)=\operatorname{Max}\left\{\sum_{t=t_{M L}}^{T} C_{t} \cdot e^{-r\left(t-t_{M L}\right)}, 0\right\}
$$

where $t_{M L}$ and $T$ represent the market launch and patent expiration time, respectively.

The exercise time for the subsequent abandon options is defined on yearly basis and the option is evaluated conditional on not having been abandoned before, therefore the time increment during 
the development phase is give by $\Delta t^{*}=1$. The backward procedure consists on discounting ${ }^{\mathrm{c}}$ the project value to the exercise time and evaluating the optimal abandon option, that is

$$
V\left(t, C_{t}, I_{t} ; \Phi^{(j)}\right)=\operatorname{Max}\left\{V\left(t+\Delta t^{*}, C_{t+\Delta t^{*}}, I_{t+\Delta t^{*}} ; \Phi^{(j)}\right) \cdot e^{-(r+\lambda) \Delta t^{*}}-I_{t}, 0\right\}
$$

The procedure continues rolling back up to the present time for those paths that are not optimally abandoned on previous interactions.

Considering 100.000 path simulations and following the above mentioned procedure, the expected patent value conditional to each state in the economic state vector is given as in Table 7

\section{[TABLE 7 AROUND HERE]}

Note that, considering the state mass probability function and equation [23], the unconditional Patent value is given by

$$
\begin{aligned}
\text { Patent Value with abandon option } & =4374 \times 1 / 3+2045 \times 1 / 3+2901 \times 1 / 3 \\
& =3106 \text { Millions } \$
\end{aligned}
$$

$$
\begin{aligned}
\text { Patent Value without abandon option } & =3864 \times 1 / 3+1564 \times 1 / 3+2854 \times 1 / 3 \\
& =2761 \text { Millions } \$
\end{aligned}
$$

Just as expected, we can clearly see that the abandon option has a significant effect over the overall project value. Moreover, comparing panel A with B, and C with D in Table 7, we can disaggregate the abandon option effect by state. Although, the abandon option has a deep impact over states 1 and 2, the effect over state 3 is rather small. Since the three states share the same investment cost schedule, the small influence of the abandon option over state 3 arises as a combination of two parameter, in this particular case a high initial cash-flow $\left(C_{0}=500\right.$ Million $\left.\$\right)$ and a rather small volatility $(\sigma=75$ Million $\$$ ). The effect of the initial cash-flow over the abandon option is fairly obvious, but the incidence of the volatility is somehow subtle. Increasing the volatility parameter derives in a much uncertain state, meaning that the cash flow stream could yield a much larger or smaller than expected value. The upside risk, that is the risk of obtaining a higher than expected cash flow, increases the project value. On the other hand, the downside risk, that is the risk of obtaining a smaller than expected cash flow or even a negative cash flow, is limited by the abandon

${ }^{\mathrm{c}}$ Note that during the development phase the discount factor is given by $e^{-r_{d} t}=e^{-(r+\lambda) t}$, where $\lambda$ represents the annual rate of failure and can be considered as a technical or technological risk premium. 
option. Hence, in terms of real options valuation, increasing the volatility derives in a higher project value because we are increasing the upside risk while the downside risk is limited, this effect is measured by the greek "Vega" which will be analysed in further detail later on. Furthermore, comparing panel A with $\mathrm{C}$, and $\mathrm{B}$ with $\mathrm{D}$ in Table 7 we can analyse the effect of the economic force over each state. As stated in the previous section, the impact of the economic force might varies across projects and states. Indeed, we can see that the economic force boosts the value of states 1 and 2 , notoriously it has a negative effect over state 3. This effect might be explained by the sensitivity of each Pharmaceutical company to economic and market conditions, we have to remember that states 1 and 2 correspond to the benchmark medicines Januvia and Janumet, respectively, both of them commercialized by Merck \& Co., Inc. On the other hand, state 3 corresponds to Humalog which is commercialized by Eli Lilly and Company.

Moreover, Table 8 disaggregates by state and period the number of paths optimally abandoned, that is the number of abandon options exercised. We have already stated that the first exercise date is at market launch. Since the net cash flow stream takes into consideration not only the sales revenues but also the production and marketing cost this variable can, and indeed does, become negative for some paths. Hence, it may be optimally exercised the abandon option although there is no further investment in developing the drug at market launch. In fact, out of 100.000 simulations this is the case for $17.997,22.277$, and 2.837 paths in the $\Phi^{1}, \Phi^{2}$, and $\Phi^{3}$ state, respectively. Of course, the likelihood of exercising the abandon option at market launch increases as the economic state worsens and vice versa. Conditional on not having been abandoned before, the abandonment decisions at each period are fully determined by the investment schedule and the economic state. Furthermore, the aggregated abandon rate by state is $20.65 \%, 27.56 \%$, and $5.01 \%$ for the $\Phi^{1}, \Phi^{2}$, and $\Phi^{3}$ state, respectively.

\section{[TABLE 8 AROUND HERE]}

Tables 9 to 11 present the conditional state value variation with respect to changes in $C_{0}$ and $\sigma$, while Figures 8 to 10 show the consequent sensitivity surface. From the option pricing literature we know that the greek "Vega" tells in what direction and to what extent the option price will move if there is a positive change in the volatility parameter, and only in this parameter. Furthermore, we also know that Vega is always positive regardless if it is a put or call option. Looking the tables by columns, that is the patent value for different choices of the volatility parameter and fixed initial cash flow, we can clearly see that in every case the patent value increases as the volatility does. A more obvious result is revealed looking the tables by rows, that is the patent value for different choices of the initial cash flow parameter and fixed volatility, we see that the patent value increases as the initial net cash flow does. 


\section{[TABLES 9 TO 11 AROUND HERE]}

\section{[FIGURES 8 TO 10 AROUND HERE]}

Besides, Figure 11 presents a stress test analysis, that is how the patent value reacts to changes in the mass probability function. We can see that the mass probability space is a triangle where is always true that $\sum_{j} g\left(\Phi^{(j)}\right)=1$. This figure is quite revealing, indeed it covers the whole economic subspace and tells us how the patent value varies to any possible combination of intensities in the economic force. However, for any economic state vector with more than three components, that is $j \geq 4$, the figure will produce a hyper-volume in a $j$-dimensional space.

\section{[FIGURE 11 AROUND HERE]}

Finally, Figure 12 presents the cash flow histogram by state at two different points in the market phase, these are Market launch and Patent expiration. The dispersion in the distribution is a direct consequence of the estimated volatility, thus state 1 presents a much more dispersed distribution than state 3, both at Market launch and Patent expiration, deriving in a higher value of the abandon option. Furthermore, the red dotted line represents the mean cash flow distribution, which is fully determined by the economic impact and the initial cash flow.

\section{[FIGURE 12 AROUND HERE]}

\section{Concluding remarks}

In this paper we have developed a novel valuation model and methodology to value a pharmaceutical $R \& D$ project based on real options approach. The posited model takes into account the interaction of market and economic forces, and the effect of these risk factors in terms of asset pricing. In Section 3, we have identified those economic risk factors driving the stock return process and the risk premium associated with each individual factor. For this endeavour we have analysed two major economic forces, namely the term yield spread and the VIX index, and we have disentangled the interaction of risk factors via spectral analysis. Our findings show that exposure to those factors with period $2.4,5.5$, and 8 years provide significant premium rewarded and should be consider in the valuation process.

In order to incorporate these risk factors and account for economic risk, we have incorporated a novel economic state vector where each economic state captures the interaction among different market and economic forces using Fourier series as the particular basis for the economic function space. In this sense, Fourier series allows us to properly define an economic scenario where the project will be developed and it is considered as an aggregate of forces playing a relevant role in 
the process evolution and determining the cash flow structure. On this regards, Fourier series is a powerful mathematical instrument which allows us to define the economic state scenario as much sophisticated as we want increasing the number of forces affecting the evolution of the project. In fact, Fourier series provides a great deal of flexibility as, by Carleson's theorem, it converges almost everywhere for a $L^{2}$ function.

In Section 5, we have illustrated the application of this model and methodology with a simple numerical example which attempts to value an $R \& D$ project to engineer a new diabetes medication. To keep the example as simple as possible we have only considered three different states in the economic state vector, each of them represents an economic benchmark determined by the top-3 best selling diabetes medicines commercialized by American Pharmaceuticals, these are Januvia, Janumet, and Humalog, the first two commercialized by Merck \& Co., Inc., and the third one by Eli Lilly and Company. Under this framework, we have performed 100.000 path simulations for each economic state and we have valued the aforementioned project. Furthermore, we have performed a sensitivity and stress test analysis for some relevant parameters and we have compared the valuation results with the project value obtained with and without the economic risk factors and with and without the abandon option.

The model and methodology presented in this paper constitute a powerful and yet simple valuation instrument with strong practical applications. As stated above, the pharmaceutical industry is extremely complex and competitive and most companies have to choose with financial wisdom each project. There are several forces, both economic and technical, driving the drug development process that are not fully understood. On this regards, our proposed model tackles all those forces playing a significant role in the project valuation process in a very simple manner and provides a comprehensive tool for the decision making process. The model and methodology here proposed can be easily extrapolated to any other industry or corporate project.

\section{Acknowledgements}

We are very grateful for the comments and suggestions received from all the attendants at the ICRA6 International Conference on Risk Analysis (Barcelona, Spain), 32nd International Conference of the French Finance Association (Cergy, France), 5th International Conference of the Financial Engineering and Banking Society (Nantes, France), 22nd Annual Conference of the Multinational Finance Society (Halkidiki, Greece), XXIII Foro de Finanzas, Meeting of the Spanish Finance Association (Madrid, Spain), and also to all the attendants at the research seminar offered at Maastricht University for their many helpful suggestions. The usual caveat applies. 


\section{References}

[1] Alexander, D.R., M. Mo, M., A.F. Stent, "Arithmetic Brownian motion and real options", (2012) European Journal of Operational Research, Volume 219, Issue 1, 16 May 2012, Pages $114-122$.

[2] Berk, J.B., R.C. Green, and V. Naik, "The Valuation and Return Dynamics of New Ventures", (2004) Review of Financial Studies, 17, 1-35.

[3] Brealey, R. and Myers S., "Principles of Corporate Finance", (2000) McGraw-Hill.

[4] Campbell, Johny. and Tuomo Vuolteenaho. "Bad Beta, Good Beta", American Economic Review, 2004, v94 (5,Dec), 1249-1275.

[5] Chen, L., "Interest rate dynamics, derivatives pricing, and risk management", (1996) SpringerVerlag, Berlin.

[6] Copeland, T.E. and V. Antikarov, "Real Options, a Practitioners Guide", Texere LLC, New York (2001).

[7] DiMasi, J.A., Hansen, R.W., Grabowski, H.G., Lasagna, L., "Cost of innovation in the pharmaceutical industry", (1991) Journal of Health Economics 10, 107-142.

[8] DiMasi, J.A., Hansen, R.W., Grabowski, H.G., "The price of innovation: new estimates of drug development costs", (2003) Journal of Health Economics 22, 151-185.

[9] DiMasi, J.A., Hansen, R.W., Grabowski, H.G., "Innovation on the Pharmaceutical Industry: new estimates of R\&D costs", November 18, 2014, Tufts Center for the Study of Drug Development

[10] Fama, Eugene F. and Kenneth R. French, "Business conditions and expected returns on stocks and bonds", (1989) Journal of Financial Economics 25, 23-49.

[11] Fama, Eugene F. and MacBeth, James D., "Risk, return, and equilibrium: Empirical tests", (1973) Journal of Political Economy, 81 (3), 607.

[12] Gamba, A. and L. Trigeorgis, "An Improved Binomial Lattice Method for Multi-Dimensional Options", Applied Mathematical Finance, Volume 14, Issue 5, pp 453-475, (2007).

[13] Hansen, R.W., "The pharmaceutical development process: estimates of current development costs and times and the effects of regulatory changes", In: Chien, R.I. (Ed.), (1979) Issues in Pharmaceutical Economics. Lexington Books, Lexington, MA, pp. 151-187. 
[14] Huchzermeier, Arnd and Christoph H. Loch, "Project Management Under Risk: Using the Real Options Approach to Evaluate Flexibility in RD." (2001) Management Science 47(1):85-101. http://dx.doi.org/10.1287/mnsc.47.1.85.10661

[15] Iain M. Cockburn, Rebecca M. Henderson "Publicly Funded Science and the Productivity of the Pharmaceutical Industry", in Adam B. Jaffe, Josh Lerner, and Scott Stern, eds., NBER Innovation Policy and the Economy, vol. 1 (Cambridge, Mass.: National Bureau of Economic Research, 2000), pp. 1-34.

[16] Kitchin, Joseph. "Cycles and Trends in Economic Factors". (1923) Review of Economics and Statistics 5 (1): 10-16

[17] Loch, C. H., and S. Kavadias (2002), "Dynamic Portfolio Selection of NPD Programs using Marginal Return", (2002) Management Science, 48, 1227-1241.

[18] Majd, Saman and Robert S. Pindyck, "Time to Build, Option Value, and Investment Decisions", Journal of Financial Economics, Vol. 18, (March 1987), pp. 7-27.

[19] McDonald, Robert L. and Daniel Siegel. "The Value of Waiting to Invest", Quarterly Journal of Economics, Vol. 101, No. 4, (November 1986), pp. 707-727.

[20] Merton, R.C. (1973). Theory of Rational Option Pricing. Bell Journal of Economics and Management Science, 4, 1, 141-183.

[21] Pennings, E. and Sereno L., "Evaluating pharmaceutical R\&D under technical and economic uncertainty", European Journal of Operational Research, Volume 212, Issue 2, 16 July 2011, pp 374-385.

[22] Pharmaceutical Research and Manufacturers of America. 2015 biopharmaceutical research industry profile. Washington, DC: PhRMA; April 2015.

[23] Pindyck R.S., "Investments of Uncertain Cost", Journal of Financial Economics, vol. 34, pp. 53-76, (1993).

[24] Posner M. J. M. and D. Zuckerman, "Optimal R\&D Programs in a Random Environment", Journal of Applied Probability, Vol. 27, No. 2 (Jun., 1990), pp. 343-350

[25] Schwartz, E.S., "Patents and R\&D as Real Options", Economic Notes, 33:1 (2004), pp. 23-54.

[26] Smith, J.E., R.F. Nau, "Valuing risky projects: Option pricing theory and decision analysis", (1995) Management Science, 41 (5) (1995), pp. 795-816. 
[27] Trigeorgis L., "The Nature of Option Interactions and the Valuation of Investments with Multiple Real Options", The Journal of Financial and Quantitative Analysis, Vol. 28, No. 1. (Mar., 1993), pp. 1-20. 


\section{Appendix of tables}

Parameters estimates. Term Yield Spread

\begin{tabular}{|c|c|l|}
\hline \multicolumn{3}{|c|}{ Estimates } \\
\hline \hline$A_{1}=0.4509(0.0056)$ & $f_{1}=0.0302$ & Period $\approx 33$ years \\
$\phi_{1}=6.2129(0.0164)$ & & \\
\hline \hline$A_{2}=0.9256(0.0074)$ & $f_{2}=0.1209$ & Period $\approx 8$ years \\
$\phi_{2}=3.4761(0.0079)$ & & Period $\approx 5.5$ years \\
\hline \hline$A_{3}=0.6949(0.0076)$ & $f_{3}=0.1813$ & \\
$\phi_{3}=0.4706(0.0154)$ & & Period $\approx 2.4$ years \\
\hline \hline$A_{4}=0.3704(0.0074)$ & $f_{4}=0.4231$ & \\
$\phi_{4}=3.8037(0.0198)$ & & \\
\hline
\end{tabular}

Table 1: This table presents the four terms Fourier expansion parameters estimates for the Term Yield Spread time series.

Parameters estimates. VIX index

\begin{tabular}{|c|c|c|}
\hline \multicolumn{3}{|c|}{ Estimates } \\
\hline \hline$B_{1}=6.8246(0.0846)$ & $g_{1}=0.0970(0.0003)$ & Period $\approx 10$ years \\
$\varphi_{1}=0.3535(0.0237)$ & & \\
\hline
\end{tabular}

Table 2: This table presents the one term Fourier expansion parameters estimates for the VIX time series. 
Factors premium

\begin{tabular}{ccccccc}
\hline \hline Period (years) & - & 33 & 8 & 5.5 & 2.4 & 10 \\
1 Factor & $\hat{\lambda_{0}}$ & $\hat{\lambda_{1}}$ & $\hat{\lambda_{2}}$ & $\hat{\lambda_{3}}$ & $\hat{\lambda_{4}}$ & $\hat{\lambda}_{5}$ \\
\hline \multirow{2}{*}{ Mean } & 0.9654 & 0.1194 & - & - & - & - \\
t-stat & 1.5817 & 0.6528 & - & - & - & - \\
& & & & & & \\
Mean & 1.1648 & - & 1.3547 & - & - & - \\
t-stat & 2.7970 & - & 2.4566 & - & - & - \\
& & & & & & \\
Mean & 1.0749 & - & - & 0.7097 & - & - \\
t-stat & 2.6499 & - & - & 2.6681 & - & - \\
& & & & & & \\
Mean & 1.3411 & - & - & - & -0.8503 & - \\
t-stat & 3.0361 & - & - & - & -2.2970 & - \\
& & & & & & \\
Mean & 2.6163 & - & - & - & - & 1.7877 \\
t-stat & 3.3248 & - & - & - & - & 2.6027 \\
\hline
\end{tabular}

Table 3: This table presents the estimated premium rewarded to a particular risk factor exposure. 
Factors premium

\begin{tabular}{|c|c|c|c|c|c|c|}
\hline Period (years) & - & 33 & 8 & 5.5 & 2.4 & 10 \\
\hline 5 Factors & $\hat{\lambda_{0}}$ & $\hat{\lambda_{1}}$ & $\hat{\lambda_{2}}$ & $\hat{\lambda_{3}}$ & $\hat{\lambda_{4}}$ & $\hat{\lambda_{5}}$ \\
\hline Mean & 1.9564 & -0.3236 & -1.4373 & 1.4821 & -0.8993 & -0.7369 \\
\hline t-stat & 2.3342 & -1.2012 & -1.0422 & 2.1351 & -2.3204 & -0.7079 \\
\hline 4 Factor & $\hat{\lambda_{0}}$ & $\hat{\lambda_{1}}$ & $\hat{\lambda_{2}}$ & $\hat{\lambda_{3}}$ & $\hat{\lambda_{4}}$ & $\hat{\lambda_{5}}$ \\
\hline Mean & 2.1609 & - & -1.2958 & 1.5219 & -0.8353 & -0.6421 \\
\hline t-stat & 2.4200 & - & -1.0125 & 2.1019 & -2.3579 & -0.6550 \\
\hline Mean & 1.9656 & -0.3079 & - & 1.5327 & -0.8895 & -0.8114 \\
\hline t-stat & 2.3660 & -1.1727 & - & 1.8712 & -2.4153 & -0.6541 \\
\hline Mean & 2.1254 & -0.2685 & -1.2407 & 1.4610 & -0.8711 & - \\
\hline t-stat & 2.4934 & -1.0687 & -1.0605 & 2.1741 & -2.3909 & - \\
\hline 3 Factors & $\hat{\lambda_{0}}$ & $\hat{\lambda_{1}}$ & $\hat{\lambda_{2}}$ & $\hat{\lambda_{3}}$ & $\hat{\lambda_{4}}$ & $\hat{\lambda_{5}}$ \\
\hline Mean & 2.5676 & - & - & 0.2685 & -0.8984 & 1.6996 \\
\hline t-stat & 2.3745 & - & - & 0.7618 & -2.4194 & 1.5496 \\
\hline Mean & 0.9642 & - & -3.8231 & 2.4420 & -0.6819 & - \\
\hline t-stat & 2.4057 & - & -1.6268 & 2.1164 & -1.9421 & - \\
\hline Mean & 2.3439 & -0.3112 & - & 0.9700 & -0.9092 & - \\
\hline t-stat & 2.5206 & -1.1811 & - & 2.8070 & -2.4006 & - \\
\hline
\end{tabular}

Table 4: This table presents the estimated premium rewarded for several combinations of risk factors exposure. 
Development phase schedule

\begin{tabular}{|c|c|c|c|c|c|c|c|c|c|c|}
\hline $\begin{array}{c}\text { Development } \\
\text { stage }\end{array}$ & \multicolumn{2}{|c|}{$\begin{array}{c}\text { Preclinical } \\
\text { testing }\end{array}$} & \multicolumn{2}{c|}{$\begin{array}{c}\text { Clinical } \\
\text { Phase I }\end{array}$} & \multicolumn{2}{c|}{$\begin{array}{c}\text { Clinical } \\
\text { Phase II }\end{array}$} & \multicolumn{3}{|c|}{$\begin{array}{c}\text { Clinical } \\
\text { Phase III }\end{array}$} & $\begin{array}{c}\text { Regulatory } \\
\text { review }\end{array}$ \\
\hline \hline Period & 0 & 1 & 2 & 3 & 4 & 5 & 6 & 7 & 8 & 9 \\
\hline Investment & 60 & 60 & 82 & 82 & 196 & 196 & 174 & 174 & 174 & 11 \\
\hline
\end{tabular}

Table 5: This table presents the work schedule and budget for the whole development process including the regulatory approval.

Intensity parameters estimates. Meds

Estimates

\begin{tabular}{|c|c|c|c|c|}
\hline \multicolumn{5}{|c|}{ Estimates } \\
\hline \hline Medicine & $\overrightarrow{1}$ & $\begin{array}{c}\text { Factor } 2 \\
\text { Period } \approx 8 \text { years }\end{array}$ & $\begin{array}{c}\text { Factor } 3 \\
\text { Period } \approx 5.5 \text { years }\end{array}$ & $\begin{array}{c}\text { Factor } 4 \\
\text { Period } \approx 2.4 \text { years }\end{array}$ \\
\hline \hline Januvia & $\hat{A}_{0}^{1}=-608.0681(43.9219)$ & $\hat{A}_{2}^{1}=8.1830(3.1416)$ & $\hat{A}_{3}^{1}=-19.3515(4.1493)$ & $\hat{A}_{4}^{1}=-18.0127(10.1329)$ \\
\hline \hline Janumet & $\hat{A}_{0}^{2}=-558.3166(11.1398)$ & $\hat{A}_{2}^{2}=-0.9269(0.7596)$ & $\hat{A}_{3}^{2}=-2.8288(0.2174)$ & $\hat{A}_{4}^{2}=0.3097(1.2646)$ \\
\hline \hline Humalog & $\hat{A}_{0}^{3}=87.8557(0.6163)$ & $\hat{A}_{2}^{3}=-4.8234(0.9429)$ & $\hat{A}_{3}^{3}=-8.3032(0.0000)$ & $\hat{A}_{4}^{3}=11.8428(0.6504)$ \\
\hline
\end{tabular}

Table 6: This table presents the intensity parameters estimates to a particular economic risk factor for a particular benchmark medicine. 
Conditional Expected Patent Value

\begin{tabular}{|c|c|c|c|c|}
\hline \multirow{2}{*}{$\begin{array}{c}\text { Economic } \\
\text { State }\end{array}$} & $\mathrm{A}$ & $\mathrm{B}$ & $\mathrm{C}$ & $\mathrm{D}$ \\
\cline { 2 - 5 } & $4373.5044(12.2098)$ & $3864.3235(14.6124)$ & $3615.1780(11.3771)$ & $2851.5395(14.7052)$ \\
\hline \hline$V\left(t, C_{t}, I_{t} ; \Phi^{(1)}\right)$ & $2044.6319(6.5133)$ & $1564.4866(8.4452)$ & $1452.3542(5.6570)$ & $699.4146(8.4700)$ \\
\hline$V\left(t, C_{t}, I_{t} ; \Phi^{(2)}\right)$ & $2900.8647(5.2686)$ & $2853.5092(5.5206)$ & $2953.2034(5.2786)$ & $2917.4724(5.5200)$ \\
\hline$V\left(t, C_{t}, I_{t} ; \Phi^{(3)}\right)$ & $2900)$ & $2156.1422(5.9484)$ \\
\hline \hline Patent Value (error) & $3106.3337(4.9358)$ & $2760.7731(5.9191)$ & $2673.5785(4.5863)$ & \\
\hline
\end{tabular}

Table 7: This table presents the patent value conditional to each state in the state vector.

Panel A: With Fourier component and with abandon option

Panel B: With Fourier component and without abandon option

Panel C: Without Fourier component and with abandon option

Panel D: Without Fourier component and without abandon option 
Abandon rate

\begin{tabular}{|c|c|c|c|c|c|c|c|c|c|c|c|}
\hline $\begin{array}{c}\text { Development } \\
\text { stage }\end{array}$ & $\begin{array}{c}\text { Preclinical } \\
\text { testing }\end{array}$ & \multicolumn{2}{c|}{$\begin{array}{c}\text { Clinical } \\
\text { Phase I }\end{array}$} & \multicolumn{2}{c|}{$\begin{array}{c}\text { Clinical } \\
\text { Phase II }\end{array}$} & \multicolumn{3}{|c|}{$\begin{array}{c}\text { Clinical } \\
\text { Phase III }\end{array}$} & $\begin{array}{c}\text { Regulatory } \\
\text { review }\end{array}$ & $\begin{array}{c}\text { Market } \\
\text { launch }\end{array}$ \\
\hline \hline Period & 0 & 1 & 2 & 3 & 4 & 5 & 6 & 7 & 8 & 9 & 10 \\
\hline Investment & 60 & 60 & 82 & 82 & 196 & 196 & 174 & 174 & 174 & 11 & 0 \\
\hline \multirow{2}{*}{ Scenario 1 } & 336 & 295 & 320 & 239 & 489 & 357 & 253 & 201 & 159 & 6 & 17997 \\
& 20652 & 20316 & 20021 & 19701 & 19462 & 18973 & 18616 & 18363 & 18162 & 18003 & 17997 \\
\hline \multirow{2}{*}{ Scenario 2 } & 721 & 560 & 597 & 558 & 894 & 685 & 537 & 396 & 327 & 12 & 22277 \\
& 27564 & 26843 & 26283 & 25686 & 25128 & 24234 & 23549 & 23012 & 22616 & 22289 & 22277 \\
\hline \multirow{2}{*}{ Scenario 3 } & 363 & 249 & 261 & 182 & 369 & 297 & 198 & 145 & 101 & 6 & 2837 \\
& 5008 & 4645 & 4396 & 4135 & 3953 & 3584 & 3287 & 3089 & 2944 & 2843 & 2837 \\
\hline
\end{tabular}

Table 8: This table presents the number of optimally abandoned projects out of 10.000 path simulations. In light gray the disaggregated by state and period number of paths optimally abandoned. In gray the aggregated by period number of paths optimally abandoned. 
$\Phi^{1}$ Sensitivities

\begin{tabular}{|r||cccccccccc|}
\hline \multicolumn{1}{|c||}{$\Phi^{1}$} & \multicolumn{10}{|c|}{$C_{0}$} \\
& 440 & 450 & 460 & 471 & 480 & 490 & 500 & 510 & 520 & 530 \\
\hline \hline 150 & 3796 & 3860 & 3900 & 3981 & 4038 & 4089 & 4137 & 4205 & 4250 & 4329 \\
160 & 3850 & 3922 & 3968 & 4032 & 4073 & 4124 & 4189 & 4264 & 4303 & 4376 \\
170 & 3913 & 3960 & 4019 & 4088 & 4120 & 4191 & 4260 & 4310 & 4348 & 4435 \\
180 & 3980 & 4031 & 4093 & 4138 & 4192 & 4261 & 4294 & 4352 & 4435 & 4478 \\
190 & 4031 & 4075 & 4162 & 4204 & 4253 & 4314 & 4399 & 4410 & 4478 & 4541 \\
200 & 4110 & 4161 & 4225 & 4275 & 4320 & 4374 & 4404 & 4471 & 4541 & 4596 \\
210 & 4183 & 4238 & 4282 & 4372 & 4402 & 4436 & 4497 & 4549 & 4600 & 4650 \\
220 & 4284 & 4319 & 4364 & 4404 & 4474 & 4511 & 4571 & 4611 & 4652 & 4766 \\
230 & 4324 & 4386 & 4434 & 4474 & 4537 & 4577 & 4627 & 4679 & 4755 & 4800 \\
240 & 4412 & 4450 & 4508 & 4560 & 4613 & 4644 & 4707 & 4756 & 4799 & 4861 \\
\hline
\end{tabular}

Table 9: This table presents the conditional to state $\Phi^{1}$ patent value sensitivity with respect to $\sigma$ and $C_{0}$. 
$\Phi^{2}$ Sensitivities

\begin{tabular}{|c||cccccccccc|}
\hline \multicolumn{1}{|c||}{$\Phi^{2}$} & \multicolumn{10}{c|}{$C_{0}$} \\
& 130 & 140 & 150 & 160 & 170 & 180 & 190 & 200 & 210 & 220 \\
\hline \hline 85 & 1579 & 1642 & 1691 & 1742 & 1801 & 1847 & 1896 & 1957 & 2006 & 2054 \\
95 & 1666 & 1719 & 1773 & 1813 & 1876 & 1925 & 1969 & 2024 & 2077 & 2130 \\
105 & 1734 & 1794 & 1848 & 1894 & 1939 & 1979 & 2034 & 2085 & 2133 & 2195 \\
115 & 1823 & 1877 & 1916 & 1966 & 2045 & 2055 & 2109 & 2173 & 2223 & 2266 \\
125 & 1915 & 1970 & 1999 & 2053 & 2094 & 2151 & 2192 & 2231 & 2289 & 2331 \\
135 & 1993 & 2042 & 2085 & 2136 & 2183 & 2214 & 2287 & 2316 & 2380 & 2418 \\
145 & 2083 & 2118 & 2170 & 2222 & 2266 & 2315 & 2348 & 2393 & 2436 & 2500 \\
155 & 2180 & 2203 & 2257 & 2289 & 2343 & 2366 & 2431 & 2481 & 2527 & 2578 \\
165 & 2247 & 2295 & 2328 & 2389 & 2438 & 2463 & 2496 & 2580 & 2604 & 2660 \\
175 & 2340 & 2398 & 2429 & 2481 & 2508 & 2561 & 2611 & 2652 & 2698 & 2723 \\
\hline
\end{tabular}

Table 10: This table presents the conditional to state $\Phi^{2}$ patent value sensitivity with respect to $\sigma$ and $C_{0}$. 
$\Phi^{3}$ Sensitivities

\begin{tabular}{|c||cccccccccc|}
\hline \multicolumn{1}{|c||}{$\Phi^{3}$} & \multicolumn{10}{c|}{$C_{0}$} \\
& 450 & 460 & 470 & 480 & 490 & 500 & 510 & 520 & 530 & 540 \\
\hline \hline 35 & 2525 & 2597 & 2661 & 2722 & 2791 & 2864 & 2929 & 3002 & 3068 & 3135 \\
45 & 2533 & 2594 & 2664 & 2728 & 2796 & 2866 & 2931 & 2997 & 3066 & 3134 \\
55 & 2544 & 2602 & 2662 & 2736 & 2804 & 2878 & 2934 & 3000 & 3069 & 3141 \\
65 & 2550 & 2619 & 2681 & 2751 & 2815 & 2878 & 2946 & 3005 & 3078 & 3147 \\
75 & 2586 & 2643 & 2712 & 2768 & 2832 & 2901 & 2975 & 3020 & 3093 & 3147 \\
$\sigma 5$ & 2613 & 2677 & 2742 & 2814 & 2867 & 2931 & 3001 & 3062 & 3112 & 3184 \\
95 & 2661 & 2731 & 2781 & 2835 & 2907 & 2968 & 3025 & 3080 & 3148 & 3204 \\
105 & 2711 & 2776 & 2834 & 2898 & 2962 & 3004 & 3074 & 3117 & 3192 & 3247 \\
115 & 2770 & 2821 & 2875 & 2936 & 3000 & 3049 & 3112 & 3185 & 3239 & 3287 \\
125 & 2823 & 2900 & 2935 & 2999 & 3065 & 3113 & 3169 & 3211 & 3278 & 3340 \\
\hline
\end{tabular}

Table 11: This table presents the conditional to state $\Phi^{3}$ patent value sensitivity with respect to $\sigma$ and $C_{0}$. 


\section{Appendix of figures}
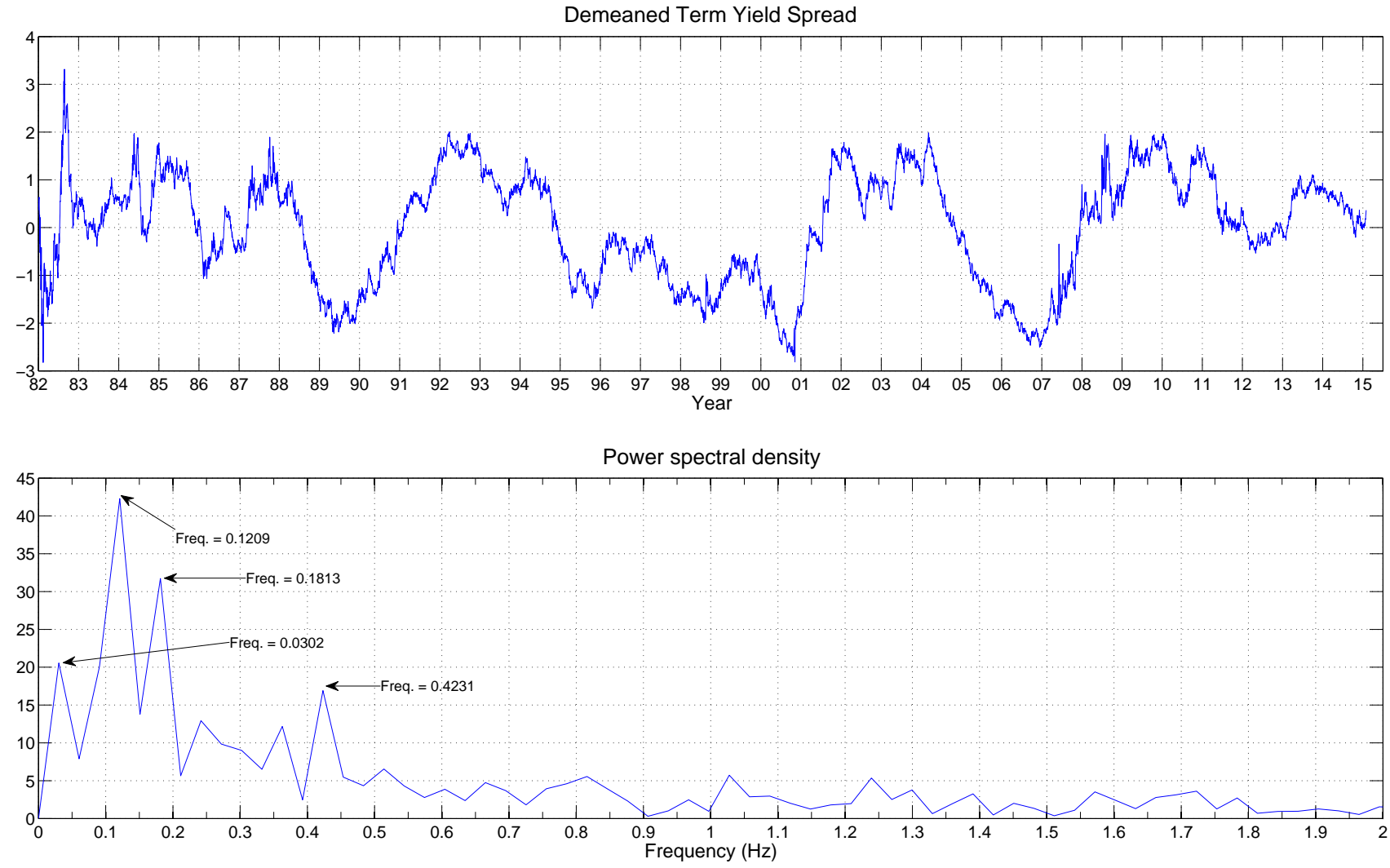

Figure 1: This figure presents the demeaned term yield spread time series and its power spectral density. 

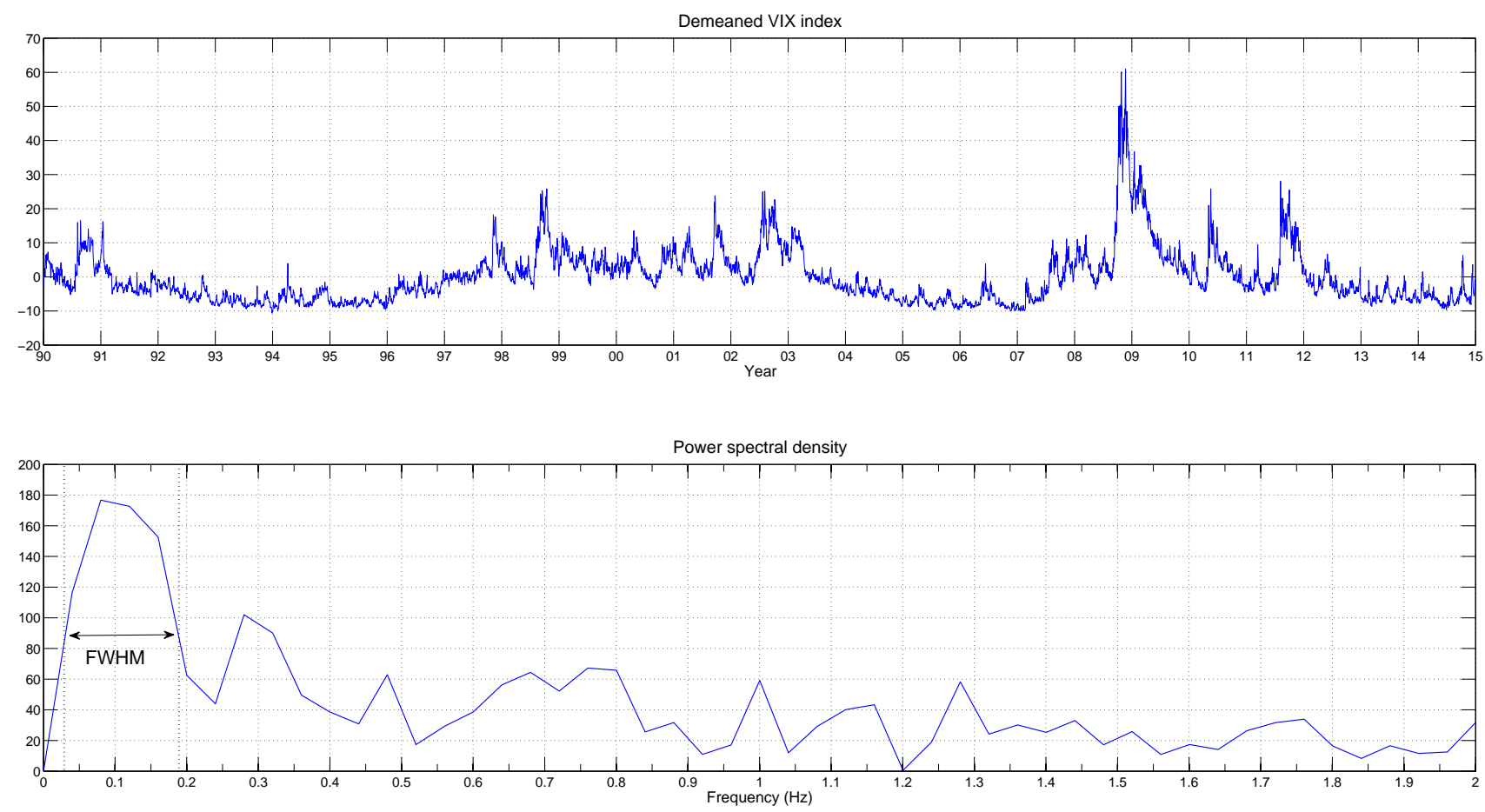

Figure 2: This figure presents the demeaned VIX index time series and its power spectral density. 


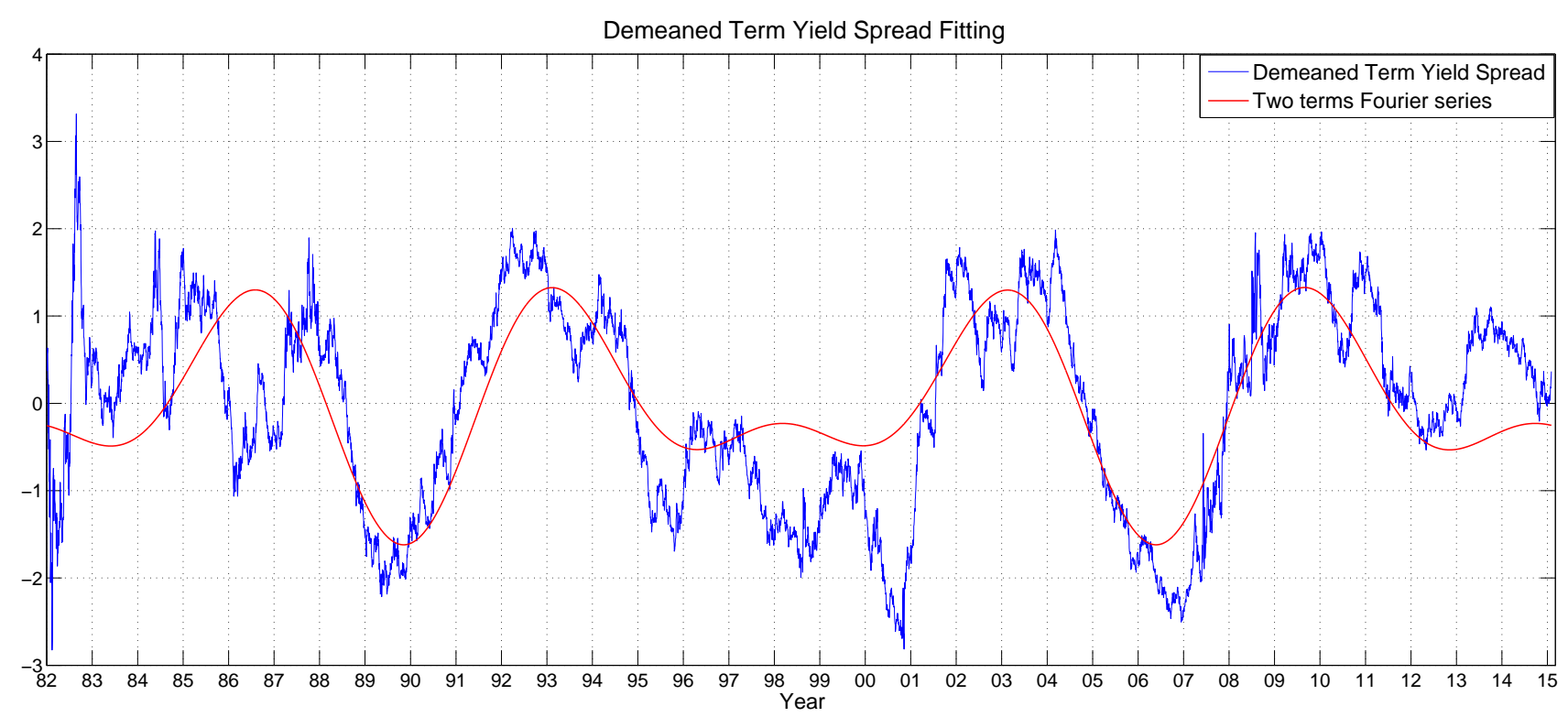

Figure 3: This figure presents the demeaned term yield spread time series versus the fitting with two terms in the Fourier expansion. 


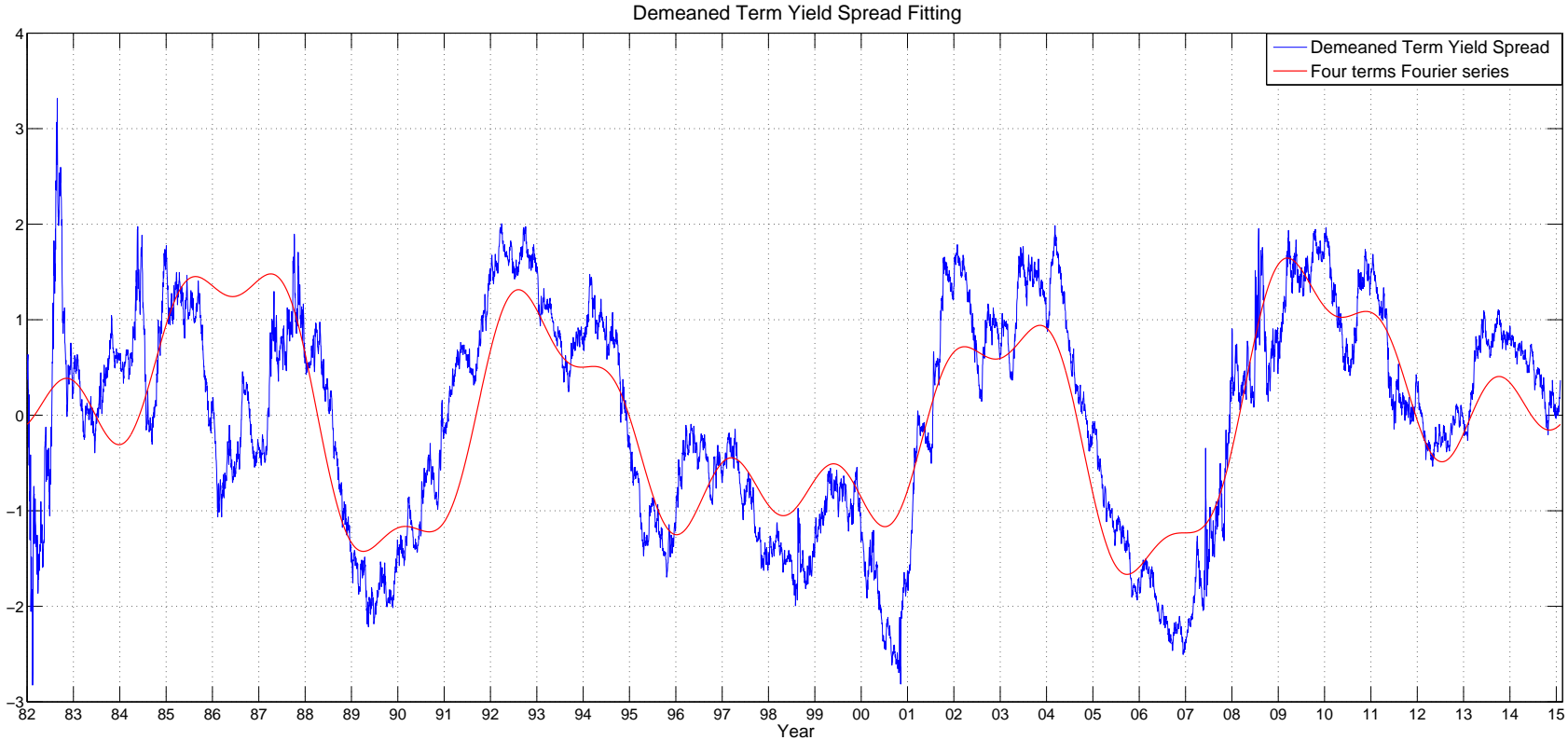

Figure 4: This figure presents the demeaned term yield spread time series versus the fitting with four terms in the Fourier expansion. 


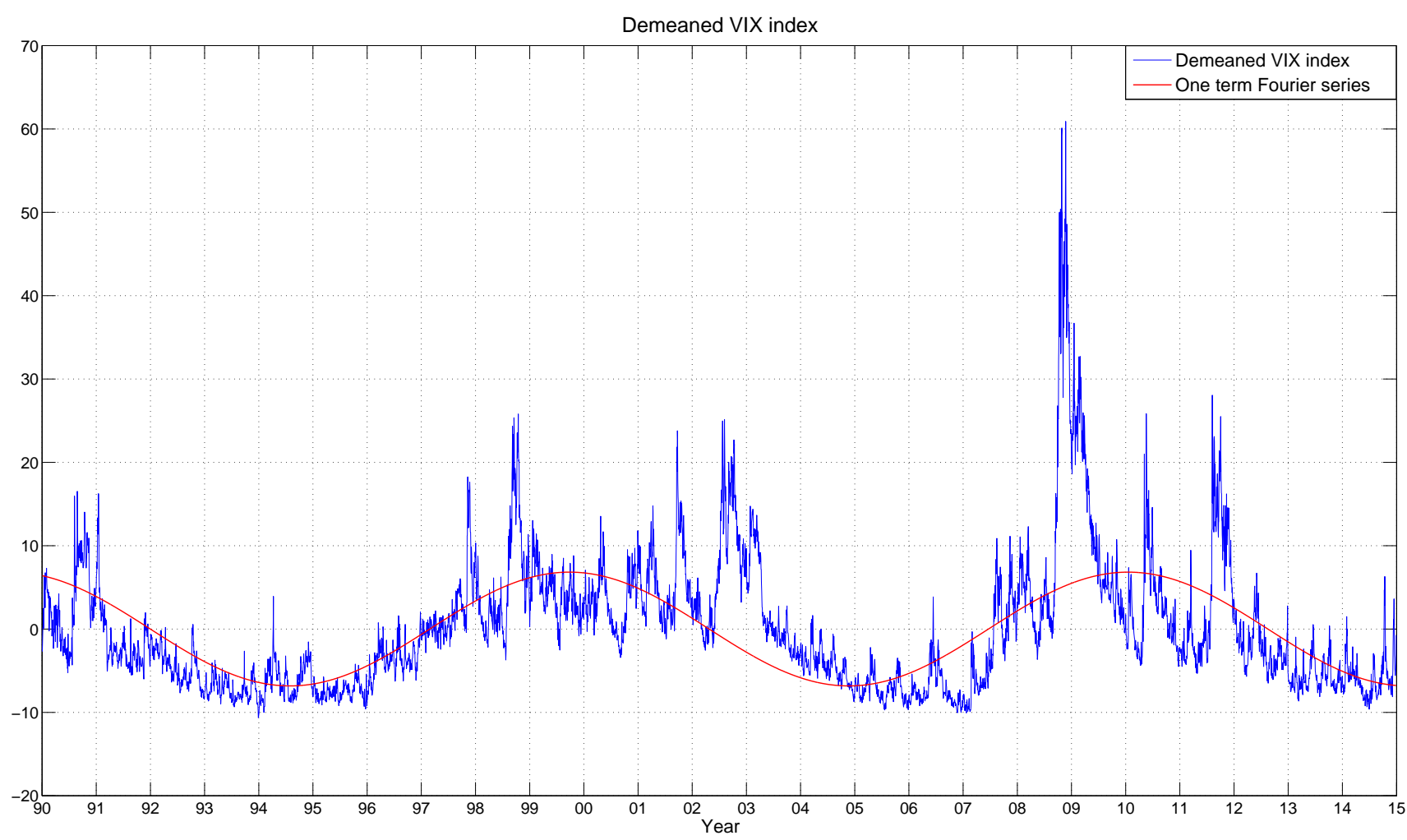

Figure 5: This figure presents the demeaned VIX index time series versus the fitting with one terms in the Fourier expansion. 


\begin{tabular}{|c|c|c|c|c|c|c|c|c|c|c|c|c|}
\hline Discovery & -1 & $\begin{array}{c}\text { Preclinical } \\
\text { Testing }\end{array}$ & -1 & $\begin{array}{l}\text { Clinical } \\
\text { Phase I }\end{array}$ & -1 & $\begin{array}{l}\text { Clinical } \\
\text { Phase II }\end{array}$ & -1 & $\begin{array}{l}\text { Clinical } \\
\text { Phase III }\end{array}$ & -1 & Approval & $\Rightarrow$ & $\begin{array}{l}\text { Market } \\
\text { Launch }\end{array}$ \\
\hline
\end{tabular}

Figure 6: This figure presents a general pharmaceutical process for the development of a new drug

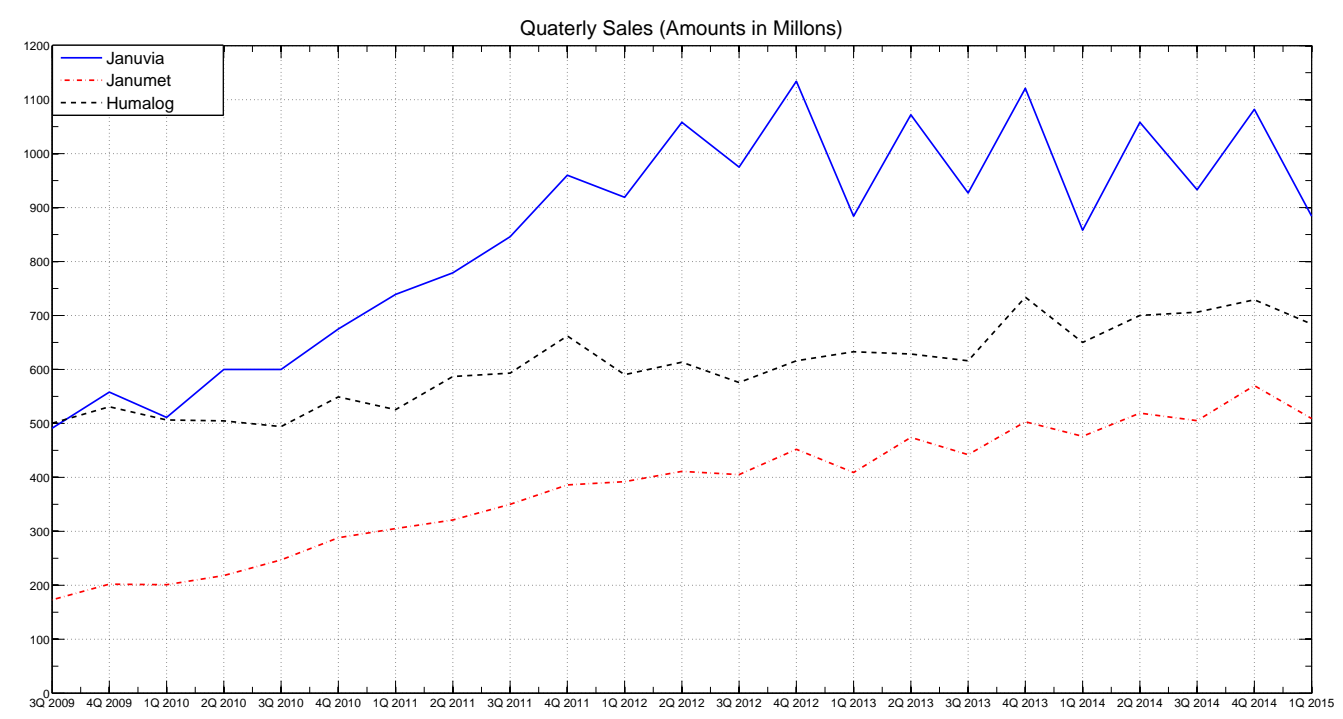

Figure 7: This figure presents the historical quarterly sales revenue stream of each benchmark drug, that is; Januvia, Janumet, and Humalog 


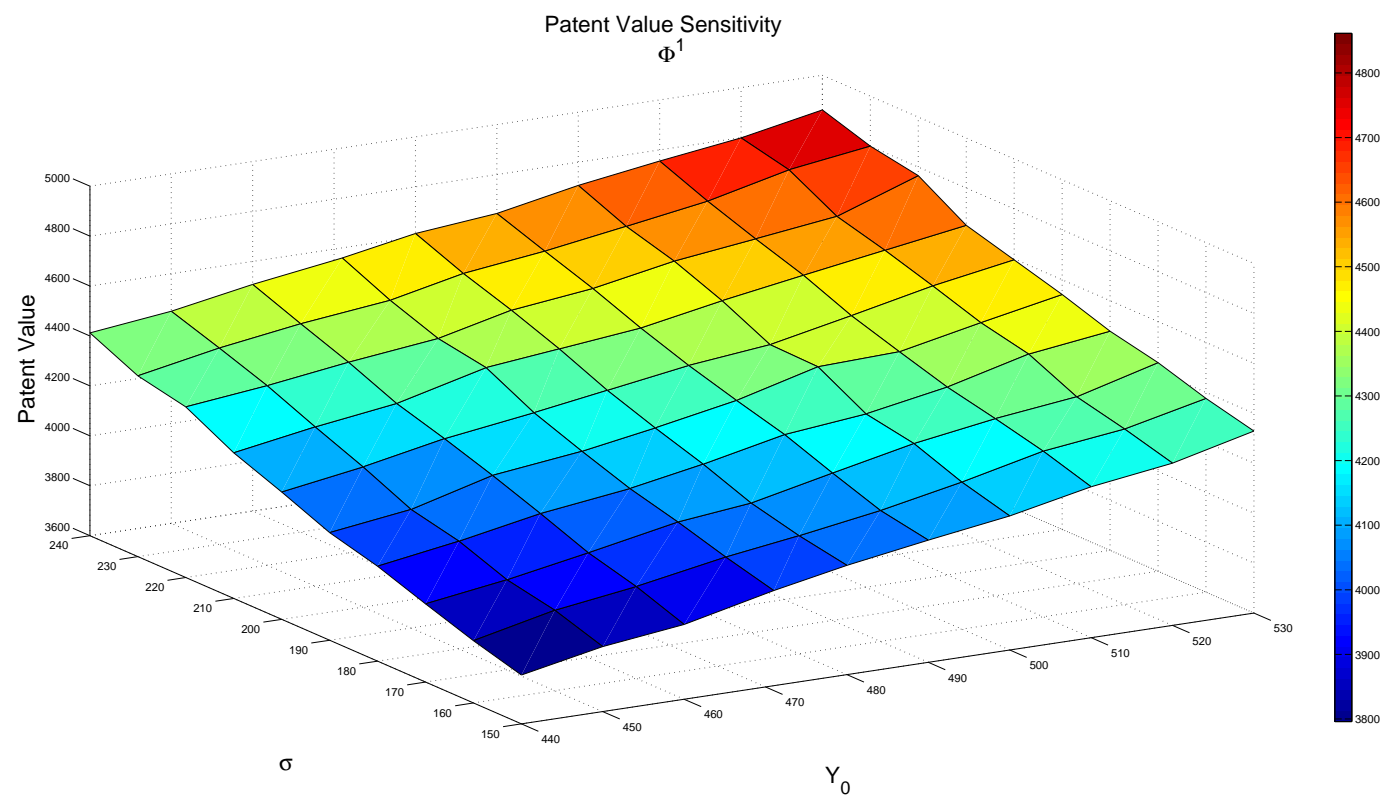

Figure 8: This figure presents the conditional to state $\Phi^{1}$ patent value sensitivity with respect to $\sigma$ and $Y_{0}$

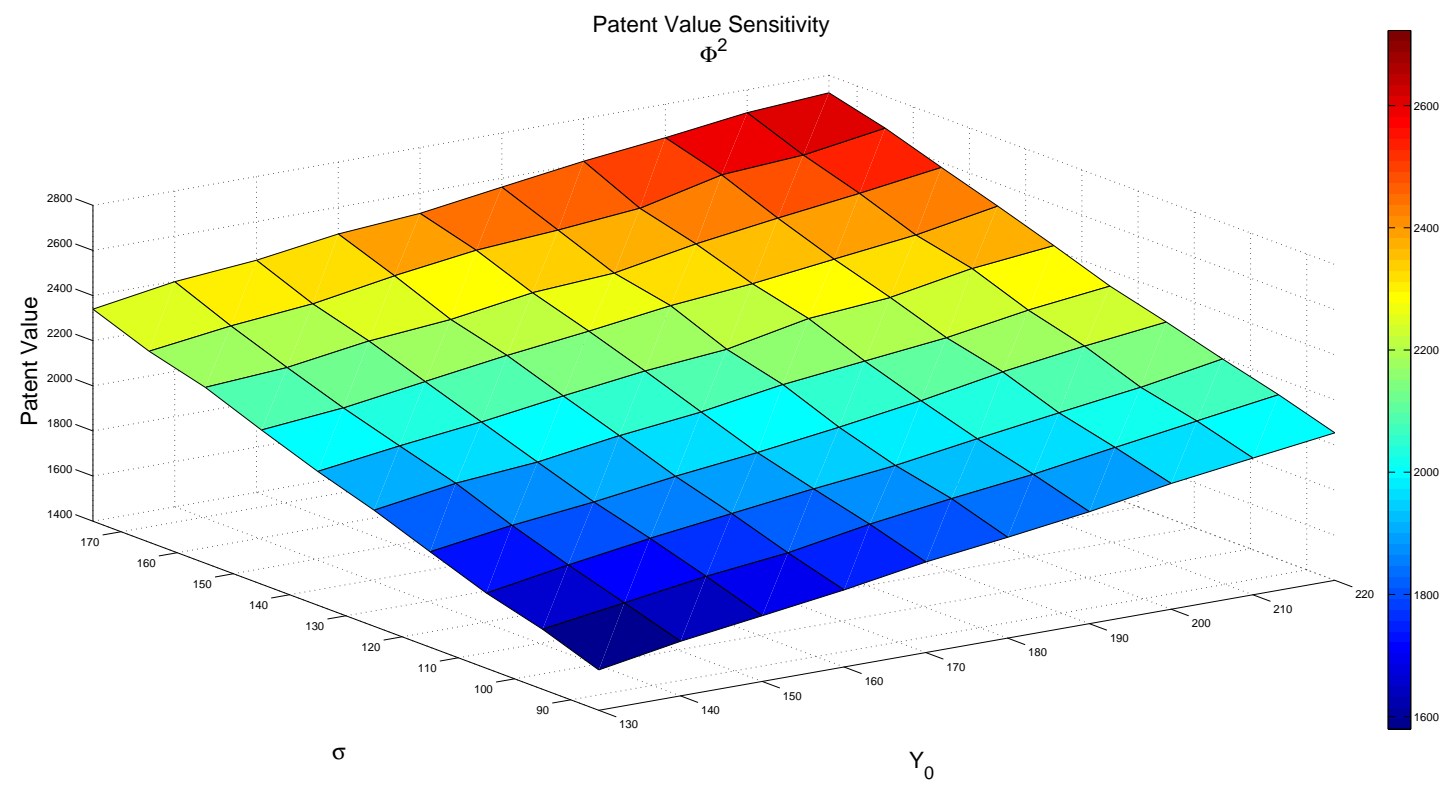

Figure 9: This figure presents the conditional to state $\Phi^{2}$ patent value sensitivity with respect to $\sigma$ and $Y_{0}$ 


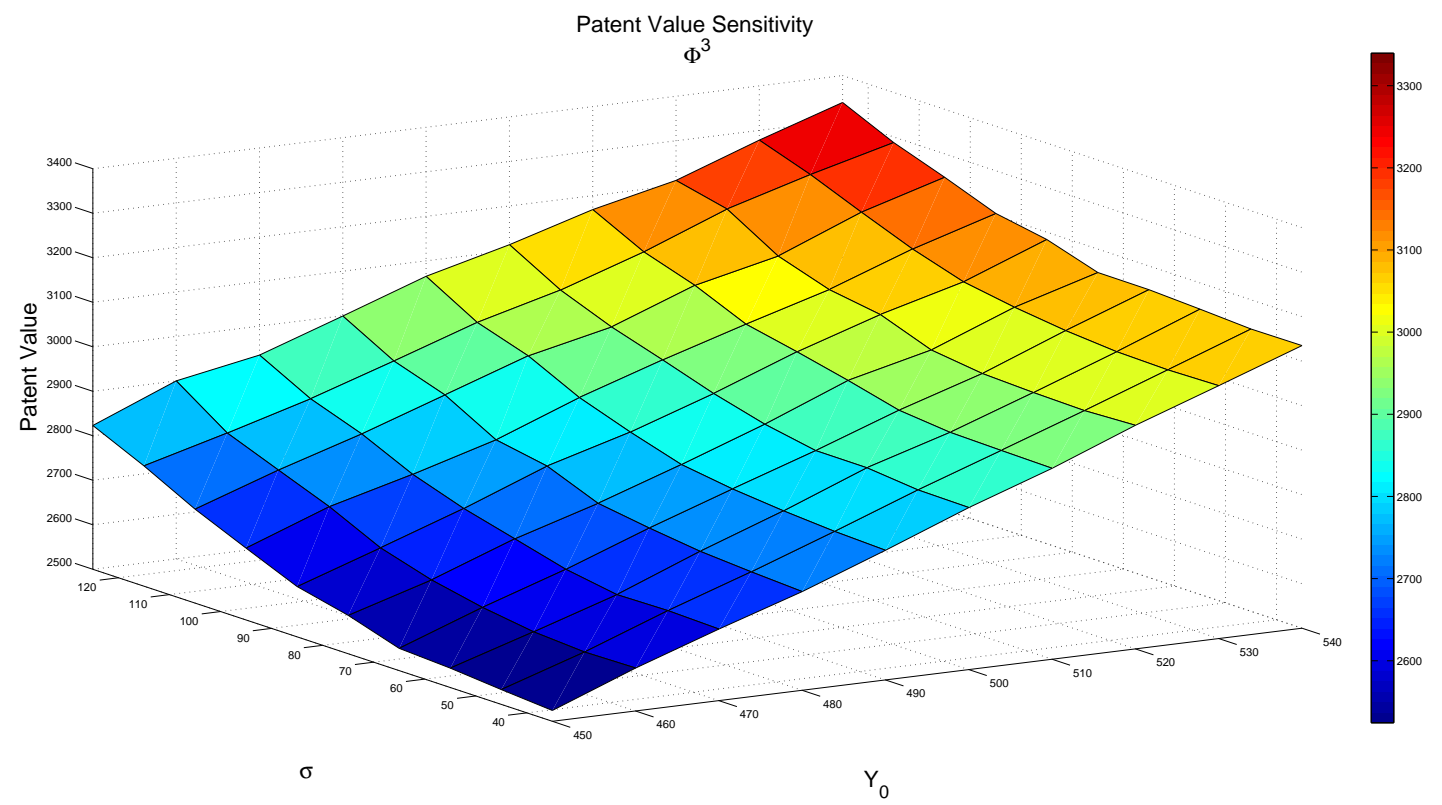

Figure 10: This figure presents the conditional to state $\Phi^{2}$ patent value sensitivity with respect to $\sigma$ and $Y_{0}$

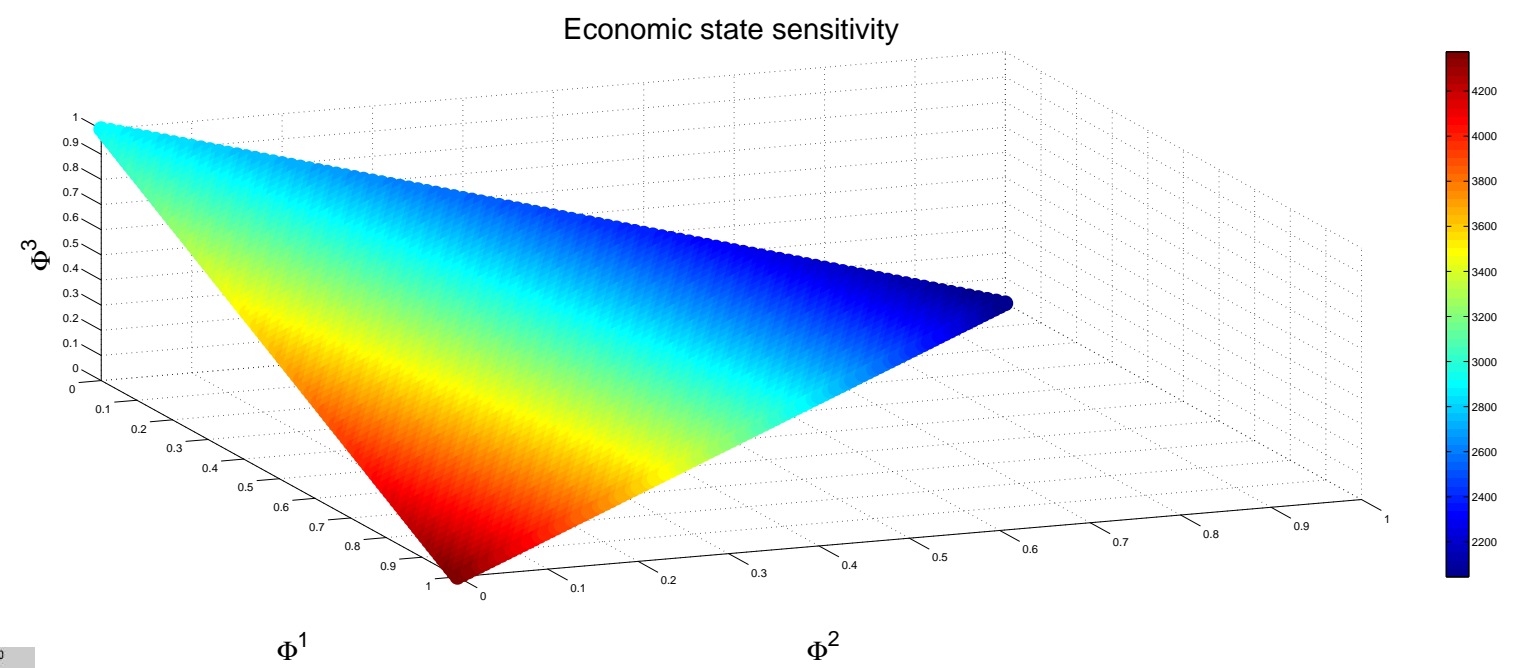

Figure 11: This figure presents the unconditional patent value sensitivity with respect to the mass probability function. 


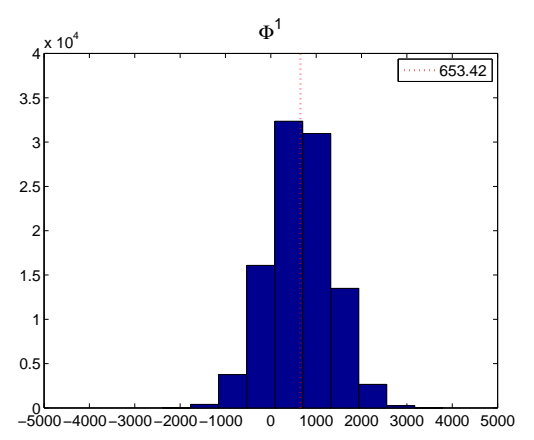

$\stackrel{\oplus}{\bullet}$
Cash Flow Histogram at Market Launch

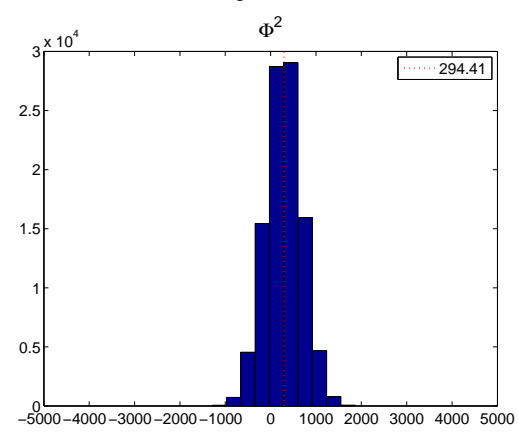

Cash Flow Histogram at Patent Expiration

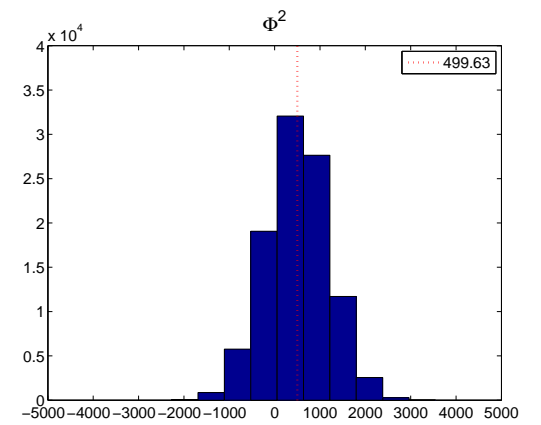

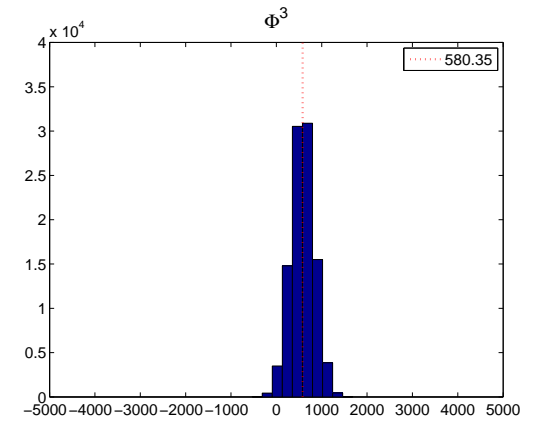

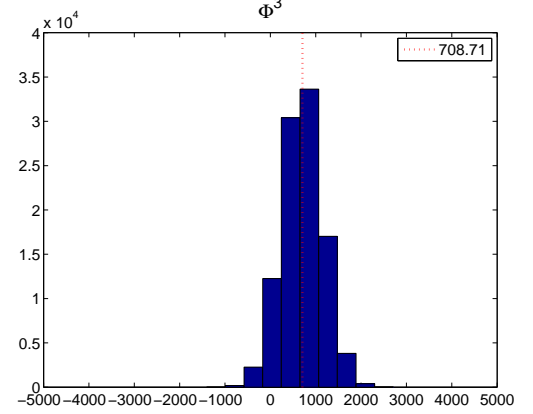

Figure 12: This figure presents the cash flow histogram by state at both market launch and patent expiration. The red dotted line represents the mean cash flow distribution. 